OPEN ACCESS

Edited by:

Andres Alcover,

Institut Pasteur, France

Reviewed by:

Salvatore Valitutti,

INSERM, France

Wendy L. Havran,

The Scripps Research Institute, USA

${ }^{*}$ Correspondence:

Janis K. Burkhardt

jburkhar@mail.med.upenn.edu

tPresent address:

William A. Comrie,

National Institute of Allergy and

Infectious Disease, National Institutes

of Health, Bethesda, MD, USA

Specialty section:

This article was submitted to

$T$ Cell Biology,

a section of the journal

Frontiers in Immunology

Received: 08 November 2015

Accepted: 12 February 2016

Published: 07 March 2016

Citation:

Comrie WA and Burkhardt JK (2016)

Action and Traction: Cytoskeletal

Control of Receptor Triggering at the

Immunological Synapse.

Front. Immunol. 7:68.

doi: 10.3389/fimmu.2016.00068

\section{Action and Traction: Cytoskeletal Control of Receptor Triggering at the Immunological Synapse}

\author{
William A. Comrie ${ }^{\dagger}$ and Janis K. Burkhardt*
}

Department of Pathology and Laboratory Medicine, Children's Hospital of Philadelphia, Perelman School of Medicine, University of Pennsylvania, Philadelphia, PA, USA

It is well known that F-actin dynamics drive the micron-scale cell shape changes required for migration and immunological synapse (IS) formation. In addition, recent evidence points to a more intimate role for the actin cytoskeleton in promoting $\mathrm{T}$ cell activation. Mechanotransduction, the conversion of mechanical input into intracellular biochemical changes, is thought to play a critical role in several aspects of immunoreceptor triggering and downstream signal transduction. Multiple molecules associated with signaling events at the IS have been shown to respond to physical force, including the TCR, costimulatory molecules, adhesion molecules, and several downstream adapters. In at least some cases, it is clear that the relevant forces are exerted by dynamics of the $T$ cell actomyosin cytoskeleton. Interestingly, there is evidence that the cytoskeleton of the antigen-presenting cell also plays an active role in T cell activation, by countering the molecular forces exerted by the T cell at the IS. Since actin polymerization is itself driven by TCR and costimulatory signaling pathways, a complex relationship exists between actin dynamics and receptor activation. This review will focus on recent advances in our understanding of the mechanosensitive aspects of T cell activation, paying specific attention to how F-actin-directed forces applied from both sides of the IS fit into current models of receptor triggering and activation.

Keywords: immunological synapse, actin, cytoskeleton, mechanotransduction, integrin, T cell receptor, adhesion, costimulation

\section{INTRODUCTION}

During their circulation through blood, lymphoid tissues, and peripheral sites of inflammation, $\mathrm{T}$ cells encounter and respond to a variety of environmental stimuli. Several of these responses are dependent on the application of external forces. A good example of this is the shear flow-induced activation of cell adhesion molecules during the slow rolling and firm adhesion steps of diapedesis, the process that brings cells from the bloodstream into tissues. Following diapedesis, T cells generate internal forces that drive their migration through the tissue stroma, in search of antigen-presenting cells (APCs) bearing major histocompatibility complex molecules loaded with their cognate peptides (pMHC). When T cells recognize these APCs, a specialized adhesive contact known as the immunological synapse (IS) is formed. The IS promotes sustained T cell/APC interactions and serves as a platform for exchange of information between the two cells. As with diapedesis and migration, $\mathrm{T}$ cell/APC adhesion and signal transduction at the IS depend on physical forces exerted by actin 
cytoskeletal dynamics. As detailed further below, actin-dependent protrusive forces drive close apposition of the two cells, bringing receptors on the T cell in contact with ligands on the APC. In addition, some IS-associated signaling molecules are physically linked to actin filaments; forces exerted on these molecules by the actin network result in conformational changes needed for full $\mathrm{T}$ cell activation.

Signaling at the IS takes place in dynamic microclusters containing surface receptors and downstream signaling molecules. These microclusters form at the periphery of the IS, within a region rich in branched actin filaments, reminiscent of the lamellipodium found at the leading edge of a migrating cell, and then move toward the center of the IS in parallel with centripetal flow of the actomyosin network (1). Importantly, ongoing actin flow is needed to sustain TCR signaling; if flow is arrested, intracellular $\mathrm{Ca}^{2+}$ levels drop, and early signaling intermediates are rapidly dephosphorylated (2). Although the signaling events that direct F-actin polymerization and cytoskeletal flow at the IS are well understood, the mechanism by which actin flow enhances $\mathrm{T}$ cell activation has remained elusive. Recent studies point to the involvement of force-induced receptor activation (3), as well as force-driven formation and centralization of signaling microclusters $(1,2,4,5)$. According to this paradigm, early signaling events drive the robust polymerization of F-actin at the IS, which in turn functions to enhance signal transduction events leading to full $\mathrm{T}$ cell activation. In this review, we will focus on the mechanisms through which cytoskeletal dynamics in T cells and APCs serve to control mechanosensitive signaling events at the IS and consider how cytoskeletal function can be included in current models of receptor triggering.

\section{F-ACTIN DYNAMICS ON THE T CELL SIDE OF THE IS}

During stimulation by an APC, T cells exhibit robust actin polymerization in the periphery of the contact area, centripetal (retrograde) flow, and eventual disassembly of F-actin filaments near the center of the contact $(2,4)$ (Figure 1). Consistent with this, actin filaments are generally shorter, more branched, and more dynamic in the periphery of the IS, where nucleation of new actin filaments and polymerization of monomers onto the growing ends of existing filaments are occurring (6). Centripetal flow of the actomyosin network is primarily driven by the polymerization of F-actin, which continuously pushes on the plasma membrane $(2,4)$. This process is accompanied by the contractile activity of non-muscle myosin IIA, which organizes actin filaments into arcs within the lamellar region. This process stabilizes the network and maintains radial symmetry. Under conditions where F-actin depolymerization is blocked, myosin activity results in network constriction. Simultaneous inhibition of F-actin polymerization, F-actin depolymerization, and myosin contractility results in complete inhibition of lamellipodial actin flow $(2,4)$. Recently, it has become evident that there are actually two pools of dynamic actin filaments at the IS. In addition to the prominent lamellipodial pool, actin polymerization also takes place in smaller actin foci, structures that are closely associated

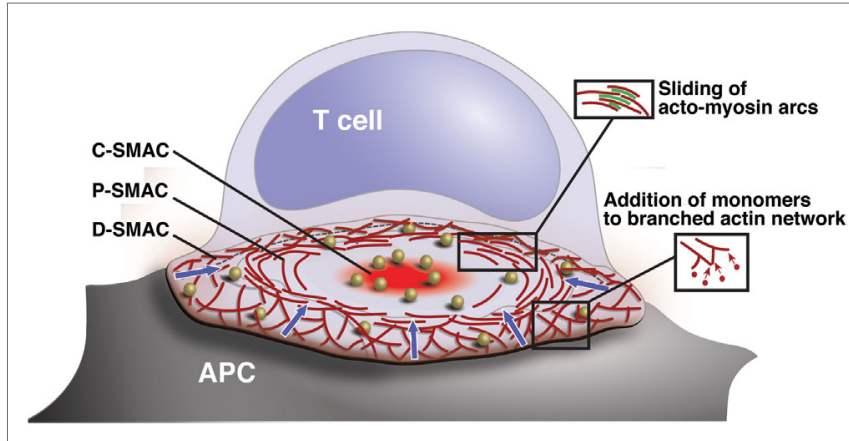

FIGURE 1 | Organization and actin dynamics within the IS. Diagram showing the architecture of a radially symmetric "bulls-eye" IS such as that formed between a B cell and an antigen-specific mature T cell. Based on molecular segregation, the IS can be divided into three regions: (1) a peripheral actin-rich region termed the distal supramolecular activation cluster (D-SMAC), (2) a deeper region rich in LFA-1 and actomyosin arcs termed the peripheral supramolecular activation cluster (pSMAC), and (3) a central region rich in $\mathrm{PKC} \theta$ and other signaling molecules termed the central supramolecular activation cluster (cSMAC). Signaling microclusters containing TCR and other signaling molecules (gold balls) form and begin to signal in the IS periphery and are transported by the cytoskeleton toward the cSMAC region, where signal extinction takes place. Microcluster movement is coupled to centripetal flow of the actin network (blue arrows). Actin flow is driven primarily by addition of actin monomers to the barbed ends of branched actin filaments, which lie just under the plasma membrane. This generates a pushing force that drives the network inward. In addition, myosin-driven sliding of actin filaments causes contraction of the network. This provides a pulling force that stabilizes the network and maintains radial symmetry.

with newly formed TCR microclusters (7). These foci are likely equivalent to the podosome- or invadopod-like protrusions (ILPs) first visualized in T cells interacting with endothelia, and later also found at the T cell/APC interface $(8,9)$. Although it has not been directly demonstrated, it seems likely that the conditions shown to arrest lamellipodial actin flow also arrest dynamics of these TCR-associated actin foci.

\section{Actin-Regulatory Pathways Downstream of the TCR}

Within the $\mathrm{T}$ cell, multiple signaling pathways, including those downstream of the TCR, CD28, and the integrin lymphocyte function-associated antigen 1 (LFA-1), lead to the activation of actin-regulatory proteins (Figure 2). The relevant signaling pathways downstream of the TCR have been reviewed extensively (10-12) and will only be briefly discussed here. Following TCR engagement, several protein tyrosine kinases, including Lck and ZAP-70, are activated, leading to the phosphorylation of multiple effectors. One key effector is the scaffold protein linker for activation of $\mathrm{T}$ cells (LAT). LAT phosphorylation recruits SLP-76 to the IS, and with it the Rho-family GTPase exchange factor (GEF) Vav1, the adapter Nck, and the IL-2-inducible T cell kinase (Itk). Activation of Vav1 and other GEFs, such as PIX and SLAT (13-15), leads to GTP loading and activation of the small GTPases CDC42 and Rac1. These GTPases, in turn, recruit and activate the actin nucleation promoting factors WASp and WAVE2, which work in concert with the related protein HS1 


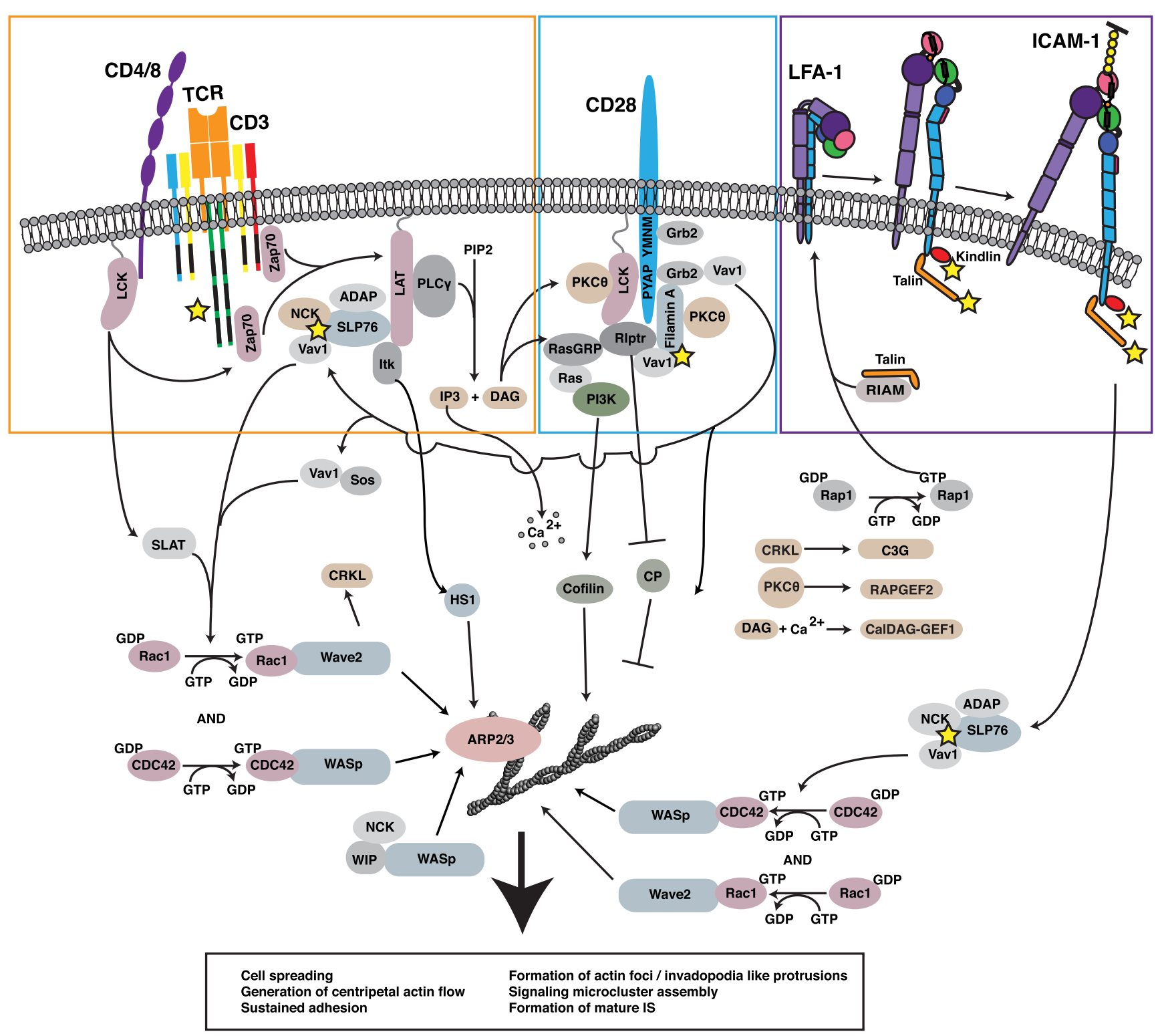

FIGURE 2 | Regulation of the F-actin network at the IS. Ligation of multiple receptors, including the TCR, the costimulatory molecule CD28, and the adhesion molecule LFA-1, results in the induction of robust actin polymerization at the IS. The pathways that mediate F-actin polymerization are highly interdependent. For example, the TCR-dependent activation of Lck is involved in initiating CD28-mediated signaling. Moreover, both TCR-induced activation and CD28-induced recruitment of PKC $\theta$ contribute to LFA-1 activation and downstream signaling. Vav1, a GEF for the critical actin regulators Rac1 and CDC42 and their respective effectors WAVE2 and WASp, is triggered in a co-operative fashion downstream of each of these key surface receptors. In addition, signaling events downstream of CD28 lead to inhibition of capping protein and activation of cofilin, events that allow growth and remodeling of the branched actin network. Together with HS1, WAVE2 and WASp activate ARP2/3 complex-dependent growth of branched actin filaments, forming lamellipodial protrusions and invadopodium-like protrusions, respectively. Collectively, these events lead to cell spreading, retrograde actin flow, and formation of the mature IS, along with assembly and centripetal flow of TCR-associated signaling microclusters. In addition to triggering actin nucleation, TCR, CD28, and LFA-1 all associate with the F-actin network (proteins known to interact with F-actin are denoted by yellow stars). In many cases, these interactions with the F-actin network serve to drive additional signaling events via actindependent feedback loops.

to orchestrate Arp2/3 complex-dependent polymerization of branched actin filaments (16-18).

Interestingly, WASp, WAVE2, and HS1 play distinct roles in organizing lamellipodial actin and actin foci. WAVE2 localizes strongly to lamellipodial protrusions and is essential for their generation $(17,19)$, whereas WASp is largely dispensable for generation of these structures (20). Instead, WASp localizes to and is essential for the formation of TCR-associated actin foci (7), further extending the similarity between these structures and podosomes in other hematopoietic cells $(21,22)$. The role of WAVE2 in generating actin foci cannot be meaningfully tested because WAVE2-deficient $\mathrm{T}$ cells do not spread in response to 
TCR engagement, but WAVE2 is absent from these structures (7). HS1 can be found in both lamellipodia and actin foci, and in its absence, both sets of structures are disordered $(7,16)$. Thus, it appears that WAVE2 organizes lamellipodia that result in T cell spreading on the APC, WASp organizes TCR-associated foci that protrude into the APC, and HS1 augments and organizes both sets of actin-rich structures.

\section{Integrin-Mediated Organization of the T Cell F-Actin Network}

Another effect of TCR signaling is to induce conformational changes in LFA-1, an integrin that mediates IS formation and firm adhesion (23). LFA-1 engagement initiates a signaling cascade that parallels and intersects with the TCR-triggered cascade. This process has been termed "outside-in" signaling to distinguish it from "inside out signaling" events that trigger initial integrin activation downstream of TCR or chemokine receptor engagement. Molecules activated downstream of LFA-1 engagement include FAK, ERK1/2, JNK, and PLC $\gamma 1$ (24-26). LFA-1 regulates F-actin through the ADAP-mediated activation of SLP-76 (27-29). This results in F-actin polymerization, likely through the Vav-mediated activation of Rac1, CDC42, WASp, and WAVE (Figure 2) (30-32). Recruitment of the Arp2/3 complex to the site of integrin engagement is enhanced by interactions of the complex with the talin-binding protein vinculin (32-34). As discussed later, integrin activation and vinculin binding to talin are dependent on the interaction of talin with the F-actin network and on ongoing F-actin flow. This suggests a robust feed-forward loop whereby integrin activation is dependent on F-actin-generated forces and results in increased activation of F-actin nucleating factors and polymerization at the IS.

Although integrin engagement can induce actin polymerization, it can also modulate F-actin flow rates. Engagement of VLA4 , a $\beta 1$ integrin expressed on activated $\mathrm{T}$ cells, by immobilized VCAM-1 greatly decreases the centripetal flow of F-actin at the IS (35). This likely occurs through the interaction of multiple actin-binding proteins with the $\beta$ chain of VLA-4, thus linking the ligand-immobilized integrin to the F-actin network and retarding network flow $(35,36)$. So, while integrins are capable of nucleating F-actin polymerization, the overall effect on the F-actin network will depend on the strength of the outside-in signal, the interaction between the integrin cytoplasmic domain and the actin network, the viscoelastic properties of the network itself, and the mobility of the integrin ligand (since only immobilized ligand could oppose forces on the integrin tail).

\section{Costimulatory Signals Leading to F-Actin Remodeling}

Coligation of the costimulatory molecule CD28 with the TCR leads to robust IL-2 production, activation, and expansion of naive $\mathrm{T}$ cells (37). The classical pathways involved with CD28 costimulation have been extensively reviewed (38-41). As part of this process, CD28 signaling regulates F-actin dynamics. CD28 can interact with F-actin through binding to filamin A (Figure 2). By binding to the adapter protein Grb-2, CD28 also promotes the formation of Vav 1/SLP-76 complexes and initiates downstream signaling (42-44). In cells in which Csk, a negative regulator of Lck, has been inhibited, CD28 binding to CD80/86 can mediate robust F-actin polymerization (45). CD28-dependent F-actin polymerization occurs through Vav-mediated activation of CDC42 and is enough to initiate cell spreading, though the appearance of the F-actin network is not as symmetrical as with TCR stimulation (46). CD28 costimulation has also been shown to induce the dephosphorylation and activation of the actinsevering protein cofilin (47). Somewhat counter-intuitively, actin severing by cofilin can increase rates of actin polymerization by providing actin monomer and freeing otherwise capped barbed ends (48). The overall effect of increasing both F-actin severing and polymerization is to create a highly branched F-actin network, a process that can strengthen lamellipodial protrusions and contribute to F-actin flow. Another molecule that is likely to participate in CD28-dependent actin responses is the lymphoid cell-specific actin-uncapping protein, Rltpr. As detailed in Section "Regulation of CD28 Signaling by the F-Actin Network," Rltpr interacts with CD28 and plays an essential role in costimulatory signaling (49). It remains to be determined if Rltpr functions to remove capping protein from barbed ends of actin filaments at the IS, but if so, this will also be important for F-actin remodeling.

In addition to CD28, it is likely that many other costimulatory proteins also modulate the $\mathrm{T}$ cell actin response. One protein known to interact extensively with F-actin is CD2. CD2 is expressed on the surface of NK cells and T cells, and it can mediate cell adhesion and induce signaling events that promote $\mathrm{T}$ cell activation $(50,51)$. Through the cytoplasmic adaptor molecule $\mathrm{CD} 2 \mathrm{AP} / \mathrm{CMS}$, CD2 engagement can recruit and activate capping protein, cortactin and WASp, facilitating the formation of a short, branched actin network (52-56).

\section{THE F-ACTIN CYTOSKELETON AND THE CONTROL OF MOLECULAR ACTIVATION AT THE T CELL-IS}

As detailed above, multiple signaling cascades converge to initiate and control F-actin flow at the IS. Conversely, however, F-actin dynamics are critical for proper signal transduction. Thus, a positive feedback loop exists whereby initial signaling events induce F-actin restructuring, which in turn reinforces and sustains signaling. In the following sections, we will describe the mechanisms by which the F-actin network can control or mediate signaling events on the T cell side of the IS.

\section{Maintaining Quiescence in Resting Cells}

The maintenance of $\mathrm{T}$ cells in a quiescent state in the absence of cognate antigen is critical for the prevention of autoimmunity and the proper regulation of the immune response as a whole. To maintain quiescence, $\mathrm{T}$ cells make use of several mechanisms. Based on work in B cells, one likely mechanism involves segregation of signaling molecules into separate cell surface compartments. As has been shown for the B cell receptor (BCR) (57), the T cell actin cytoskeleton may limit baseline signaling by preventing clustering of the TCR or downstream signaling intermediates. In fact, one way that antigen experienced cells maintain increased 
sensitivity to antigen is through the oligomerization and clustering of the TCR, suggesting that this process is, in fact, regulated (58). Additionally, it has been reported that large clusters of TCR and LAT are maintained separately in resting cells, and only overlap upon activation (59). Although LAT clusters are maintained by the actin cytoskeleton, it remains possible that actin also separates LAT and TCR clusters in resting T cells (60). Reorganization of the actin network following stimulation could then permit or drive cluster growth and molecular interactions. In B cells, actin-binding proteins of the ezrin, radixin, moesin (ERM) family limit BCR cluster formation, preventing aberrant signaling through the maintenance of diffusional barriers (57). BCR signaling transiently deactivates ERM proteins, allowing for increased BCR diffusion and cluster formation. This cycle is required for antigen capture, as both constitutively active and dominant negative ERM proteins interfere with this process (61). This shows that while ERM-mediated diffusional barriers may aid in maintaining a quiescent state, these barriers also undergo a dynamic cycle of activation and deactivation. A similar process may be occurring in T cells, since TCR stimulation also causes ERM protein dephosphorylation and cytoskeletal relaxation (62).

\section{T Cell Migration, Initial Antigen Scanning, and the Conversion to a Stable IS}

In many experimental systems, $T$ cells are introduced to stimulatory surfaces from suspension, such that initial TCR-induced actin polymerization is required for cell spreading and synapse formation. In vivo, however, initial contact between $\mathrm{T}$ cells and APCs occurs within the context of T cell migration. T cell migration requires actin-mediated protrusion of the leading edge and myosin-mediated contraction of the trailing uropod (63-65). Initial $\mathrm{T}$ cell scanning is characterized by short-lived $\mathrm{T}$ cell/ APC interactions. During these interactions, T cells form mobile synapses known as kinapses, which exhibit protein segregation patterns analogous to those seen in mature synapses, but are not radially symmetrical $(66,67)$. In essence, then, the conversion between kinapse and synapse entails altering the symmetry of the actomyosin network. This appears to be determined, at least in part, by the strength of TCR signaling. In support of this, the balance between PKCO signaling and WASp activity determines if cells are likely to break or maintain symmetry (68). Although additional details of how $\mathrm{T}$ cells maintain this balance are yet to be worked out, it has been proposed that PKC $\theta$ fosters symmetry breaking by activating localized myosin contractility (67). In addition, there is evidence that intracellular calcium levels also play an important regulatory role (69-71).

\section{Coupling of Signaling and Actin-Driven Microcluster Dynamics}

Following the formation of a stable, symmetric synapse, microclusters of TCR and downstream signaling components, such as Zap70 and SLP76, form in the periphery of the IS (peripheral supramolecular activation cluster, pSMAC) and undergo transport to the center of the contact zone (central supramolecular activation cluster, cSMAC). Depolymerization of F-actin abolishes the generation of new TCR microclusters, as well as inward movement of existing TCR microclusters $(1,72)$, but the mechanisms linking the actin cytoskeleton to microcluster formation and movement have yet to be fully worked out. Since microtubules and cytoplasmic dynein have been implicated in microcluster movement toward the cSMAC (73), one could imagine a model in which the actin network functions as a static scaffold for microcluster nucleation, with subsequent microtubule-dependent microcluster transport contingent upon maintenance of this actin scaffold. However, this model has been ruled out; when cells are treated with an inhibitor cocktail that arrests actin dynamics but leaves the network intact, the formation and translocation of SLP76 microclusters are blocked (2). Furthermore, actin flow rates are locally perturbed at TCR microclusters that encounter a barrier to inward transport (74), suggesting direct interactions between the TCR and the actin network. Although it remains unclear exactly how actin dynamics promote continued signaling from individual microclusters, arresting F-actin dynamics interrupts phosphorylation of PLC $\gamma$, resulting in a rapid drop in intracellular $\mathrm{Ca}^{2+}$ levels (2). Actin foci are likely to be the relevant actin-rich structures in this context, since loss of WASp (or HS1) inhibits PLC $\gamma 1$ activation and associated $\mathrm{Ca}^{2+}$ signaling, while loss of WAVE2 affects $\mathrm{Ca}^{2+}$ signaling at the level of CRAC channel coupling, leaving PLC $\gamma 1$ activation intact (17).

In addition to driving microcluster formation and sustaining signaling, IS-associated F-actin flow sets a molecular countdown for signal termination. Tyrosine phosphorylation of early signaling intermediates typically occurs in microclusters located in the pSMAC (72), whereas the cSMAC is an area of protein dephosphorylation, ubiquitinylation, and internalization to form IS-associated microvesicles $(75,76)$. Prolonging the time microclusters spend in the cell periphery actually prolongs signaling lifetime $(72,77)$. For example, recruitment of TCR into the CSMAC is dependent on the ubiquitin-binding protein TSG101, and knockdown of TSG101 inhibits cSMAC formation and increases microcluster lifetime and total phosphotyrosine levels at the IS (76). Thus, while dynamic actin filaments first initiate the formation of active signaling microclusters, they subsequently lead to their deactivation by driving their accumulation at the cSMAC. Interestingly, formation of TCR-enriched microvesicles occurs as a linear function of MHC density (75). Moreover, the amount of active signaling that occurs within the cSMAC varies with peptide dose and agonist strength (78). Thus, signal activation and extinction can be modulated at the level of microcluster dynamics, to tune $\mathrm{T}$ cell responses over a broad range of antigenic signals.

\section{Force Generation and T Cell Activation}

During the initial contact between a migrating T cell and an APC, and in the radially symmetric mature synapse, multiple forces are applied to the molecular contacts between the two cells. As T cells migrate on the APC surface, actin polymerization at the leading edge and myosin contractility at the trailing uropod provide this force, while at the mature IS, the retrograde F-actin flow provides a similar force. With this in mind, molecular contacts between TCR and $\mathrm{pMHC}$, integrins and integrin ligands, and costimulatory 
molecules and their ligands must persist and signal under constant strain. Interestingly, the generation of molecular forces at the IS downstream of pMHC-TCR interactions is directly correlated with the antigenicity of a given pMHC (79), and T cells respond differently depending on the mechanical properties of the stimulatory surfaces they encounter $(80,81)$. Over the stiffness ranges tested so far, it has been shown that human $\mathrm{T}$ cells respond better to substrates of increasing stiffness, and this corresponds to an increased ability to generate force at the IS along with increasing substrate stiffness $(81,82)$. Additionally, migrating $T$ cells are far more sensitive to antigen when encountered at the leading edge, rather than at the less dynamic uropod, suggesting that the forces at the leading edge prime the TCR to respond to cognate antigen $(83,84)$. This evidence suggests that mechanical force is integrally involved in $\mathrm{T}$ cell activation. If this is the case, then studying the mechanical forces on the TCR and other receptors at the IS and the relevant mechanosensitive signaling pathways becomes critically important in gaining a complete understanding of T cell activation.

\section{Cytoskeletal Forces and the Initiation and Maintenance of TCR Signaling}

Although the molecular interactions between the TCR and pMHC have been extensively characterized, the mechanism by which information on receptor ligation is transmitted across the plasma membrane and transformed into the biochemical signals associated with TCR triggering is unknown and hotly debated. Several challenges unique to the TCR/pMHC interaction must be overcome in order to initiate signaling, and any model proposed to describe TCR triggering must take these into account (85). First, TCR triggering must be extraordinarily sensitive, as there are typically only a few molecules of cognate pMHC on the surface of a given APC. Indeed, TCR triggering and T cell activation can occur in response to a single pMHC complex (86). Second, the TCR must efficiently discriminate between rare agonist and plentiful non-agonist pMHC molecules. Finally, TCR triggering must occur despite a near limitless diversity in the binding of pMHC and TCR. Several models have been proposed to account for these requirements. It is illuminating to consider these models in terms of the potential role of forces generated by F-actin at the IS. It is important to note that many observations that support a role for cytoskeletal force can be explained within the context of multiple models, and it is likely that several mechanisms are working together to initiate TCR triggering.

\section{The Kinetic-Segregation Model}

The kinetic-segregation model was proposed, in part, to account for the large proportion of Lck that is phosphorylated on the activating tyrosine, Y394, even in the absence of TCR stimulation (87). It is likely that this active Lck is continuously opposed by the action of CD45 and other phosphatases, since pharmacological phosphatase inhibition induces $\mathrm{T}$ cell activation in the absence of TCR stimulation (88-90). Additionally, removal of the Lck negative regulator $\mathrm{C}$-src tyrosine kinase (Csk) results in the activation of proximal TCR triggering events (45). It is therefore unsurprising that the balance between tonic signaling and activation of TCR signaling depends on the expression of Csk, inhibitory phosphatases such as CD45, and kinases such as Lck (91). The kinetic-segregation model proposes that close membrane apposition enforced by the TCR/pMHC bond length $(\sim 15 \mathrm{~nm})$ is too small to allow colocalization of proteins with large extracellular domains, such as CD45. In the model, the TCR is a passive player in this process, and close membrane apposition is driven entirely by the affinity of TCR for pMHC and the formation of multiple bonds leading to stochastic size-based sorting and exclusion of large molecules from pMHC/TCR rich areas. Exclusion of CD45 then allows the system to be dominated by the constantly active Lck, and TCR triggering ensues (92). Indeed, in vitro modeling of the TCR signaling network on reconstituted liposomes has shown that clustering of $\mathrm{CD} 3 \zeta$ and Lck is enough to overcome even high concentrations of CD45 and induce signaling (93), and large ectodomain proteins have been shown to enhance clustering of smaller proteins and their ligands in live cells (94). Signaling can continue following dissociation of TCR/pMHC as phosphorylated ITAMs can be protected by interaction with their specific binding partners (93).

The strongest evidence for the kinetic-segregation model is based on observations that truncation of the CD45 ectodomain (creating a shorter molecule) impairs TCR-mediated signaling, and that full function can be restored by simply adding any large ectodomain to truncated $\operatorname{CD} 45(95,96)$. Additionally, the size of the ectodomain influences segregation of CD45 and TCR into separate protein islands, with larger ectodomains resulting in greater separation. Moreover, extending the length of the extracellular domain of $\mathrm{pMHC}$ by the addition of various length tethers results in poor $\mathrm{T}$ cell activation corresponding to greater distances between the APC and T cell, and poor exclusion of CD45 from both the interfaces and from CD3 clusters $(97,98)$. Though elongated pMHC does not affect TCR or coreceptor binding or TCR clustering, it remains possible that elongation of pMHC affects the force transduced to the TCR, an idea that will be considered below.

Despite the evidence in favor of the kinetic-segregation model, several key problems have arisen in the literature. First, some authors have found that small ectodomains can result in CD45 exclusion from TCR and CD2 microclusters, as well as the total IS interface, suggesting that ectodomain size may not be the only contributing factor in this process $(91,99)$. Additionally, truncation of the intracellular domain of CD43 results in poor exclusion from the IS, suggesting that segregation based on size is not enough to determine molecular sorting at the IS for all large molecules (100). In these instances, molecular crowding and active transport may also be involved. Second, in NK cells, where similar molecular sorting events separate inhibitory and activating receptors based on ectodomain size (101), it has been found that segregation depends largely on the surface expression level of the small ectodomain protein and its receptor; more expression (and more receptor-ligand engagement) leading to greater segregation (102). This makes sense in that, in order to exclude large ectodomain proteins, the combined bond strength between shorter molecules and their ligands must be strong enough to deform the local plasma membrane and bring cells into close proximity, overcoming resistance posed by the entire glycocalyx. 
Given the generally low affinity of the TCR for pMHC, multiple interactions would be needed to provide this force. This idea is troublesome given recent evidence that only one pMHC can induce the formation of a microcluster containing hundreds of TCRs, presumably excluding CD45, on a responding T cell (86). Finally, it has been shown that TCR microclusters that exclude CD45 can form in the absence of agonist pMHC, and even in the complete absence of MHC on artificial surfaces coated with ICAM-1 (103). This observation necessitates a different mechanism besides stochastic exclusion of large molecules following TCR/pMHC bond formation to explain any size-based exclusion of CD45 from TCR microclusters.

The polymerization of the F-actin network and forces generated by the network may be enough to overcome these limitations. During kinapse formation, the T cell actin network is undergoing dynamic regulation through a combination of chemokine receptor, costimulatory molecule, and integrin-mediated signaling. This reorganization of the F-actin network may be enough to push the T cell and APC membranes close together, overcoming the charge repulsion presented by the glycocalyx (104). This force could initiate CD45 exclusion from the TCR in areas of close membrane apposition, even in the absence of TCR/pMHC interactions. Following TCR engagement, forces generated by F-actin polymerization could work in concert with the close membrane apposition enforced by TCR/pMHC interactions to propagate this process, further separating CD45 and other large ectodomain proteins from TCR microclusters, and ultimately excluding them from the mature IS. In line with this idea, it has recently been found that $\mathrm{T}$ cells can produce invadosome-like protrusions into the membrane of an APC. These protrusions can form in the absence of antigen (though their frequency and longevity are increased in the presence of antigen) and induce extremely close membrane apposition, overcoming charge repulsions mediated by the glycocalyx (8). Critically, these protrusions (which presumably correspond to the WASp-dependent actin foci described above) are completely dependent on the F-actin network, occur in multiple T cell/APC models, and precede the onset of early TCR triggering. This phenomenon likely explains why disruption of the F-actin network prevents the formation of new TCR microclusters, even in the continued contact between the T cell and an artificial APC (1), since receptor clustering would depend on proximity to $\mathrm{pMHC}$, and $\mathrm{CD} 45$ exclusion. Based on this evidence, the kinetic-segregation model can be modified to account for the contribution of F-actin-generated force in initiating close membrane apposition, particularly in the presence of low $\mathrm{pMHC}$ concentration, thus contributing to CD45 exclusion form sites of TCR-pMHC binding (Figure 3A).

\section{The Kinetic Proofreading Model}

The kinetic proofreading model of TCR triggering, initially proposed by McKeithan, posits that TCR triggering requires individual bond lifetimes above a certain threshold duration, and longer than the dissociation time (105). Furthermore, if unbinding occurs prior to this threshold being reached then no signaling occurs and the TCR resets itself. This model was later refined to allow for retention of TCR signaling intermediates, so that rebinding of pMHC to the same TCR would continue from where the previous interaction left off (106). This fits well with the observations that fast $\mathrm{pMHC}$ on rates can overcome low dwell times/high off rates and lead to high apparent affinities and TCR triggering. That is, if a pMHC rebinds prior to diffusing away from the TCR, it could induce TCR triggering by reaching the threshold even when any given interaction is particularly short $(107,108)$. In fact, in 2D experimental paradigms, $k_{\text {on }}$ has been shown to be one of the best predictors of pMHC agonist strength $(109,110)$.

Force produced by the F-actin network may play an interesting role in the kinetic proofreading model. It has recently been shown that the TCR can engage in catch-bond molecular interactions, in which applied force prolongs the interaction time with cognate pMHC (111). In that study, Liu et al. show that in the absence of force on the TCR/pMHC bond, there is an inverse relationship between the average lifetime of the bond and pMHC potency. However, following the application of $10 \mathrm{pN}$ of exogenous force to the bond, agonist pMHC bond lifetimes increase, behaving like catch-bond molecular interactions, while antagonist bond lifetimes decrease, behaving like more traditional slip-bond type molecular interactions. This leads to a 57 -fold increase in the ratio of bond lifetimes between strong agonist and strong antagonist peptides following the application of force. Additionally, catchbond behavior correlated strongly with the strength of the agonist (as measured by $\mathrm{T}$ cell stimulatory capacity) such that the strongest agonist $\mathrm{pMHC}$ had the largest increase in bond lifetime following the application of force and required the greatest force to induce the catch-bond behavior. Interestingly, it has been shown that at the IS, the actin cytoskeleton acts to decrease the half-life of some TCR/pMHC bonds (109). Thus, internally generated force provided by the F-actin network could function similarly to the external force applied in the study by Liu et al. In terms of the kinetic proofreading model, force would thus allow for increased specificity and greater bond lifetimes for agonist vs. antagonist $\mathrm{pMHC}$, enhancing sensitivity and diminishing noise during TCR signal acquisition (Figure 3B).

\section{The Serial Triggering/Serial Engagement Model}

The serial engagement model was proposed as a way of accounting for the high specificity of the TCR, despite low 3D affinities and high off rates, and low numbers of agonist pMHC on the APC surface. In this model, pMHC serially engages with multiple TCRs, triggering each one individually before moving onto another, and thereby taking advantage of the high off rate to trigger multiple receptors (112). Later studies have confirmed that a single pMHC is capable of recruiting hundreds of TCRs into a complex, initiating $\mathrm{T}$ cell activation and cytokine production (86). It has previously been proposed that actin-induced apposition of the T cell and APC membranes would bring the TCR into close proximity to $\mathrm{PMHC}$ complexes, accommodating the fast on-rates characteristic of agonist pMHC (113). It is possible that in addition to facilitating single pMHC/TCR interactions, the actin cytoskeleton also serves to bring additional TCRs into the immediate vicinity of ligated TCR/pMHC pairs. This would increase activation efficiency by reducing the time it would take for pMHC to encounter another TCR. The actin cytoskeleton is critical for the formation of TCR and signaling microclusters 
A

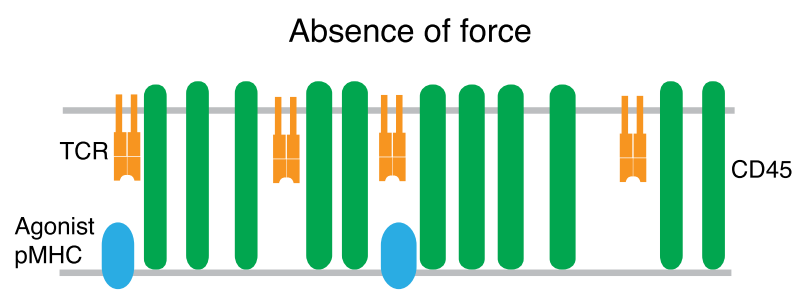

B

Kinetic Proofreading

Absence of force No difference in bond lifetimes

\section{F-actin force}

Strengthening of agonist interactions and breaking of weak agonist

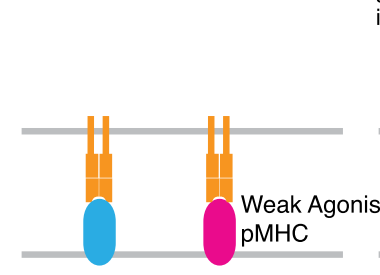

\section{Kinetic Segregation}

D

1. Force-dependent bending of the TCR causes a bending of the CD3 chains that results in TCR triggering.
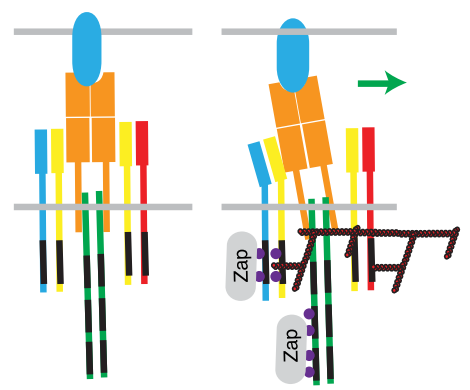

Actin flow induced force on the TCR

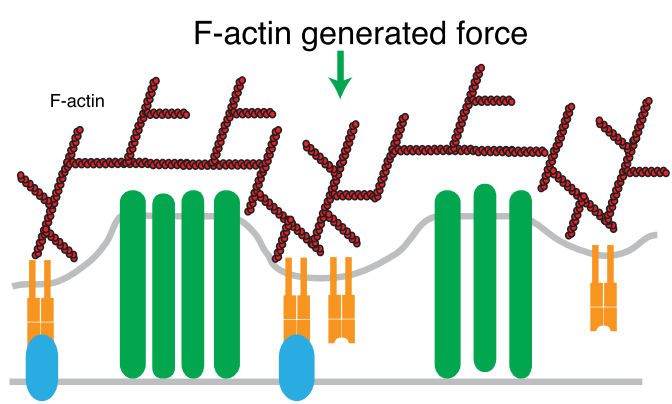

c Serial Triggering / Serial Engagement

F-actin mediated TCR clustering

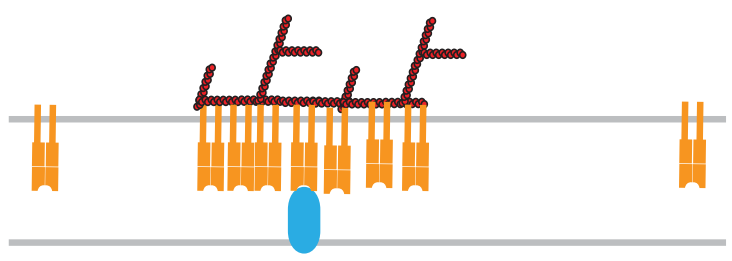

\section{FIGURE 3 | Mechanisms through which actin-dependent forces can contribute to proposed models controlling TCR triggering. (A)}

The kinetic-segregation model of TCR signaling is dependent on the separation of molecules with small extracellular regions, such as the TCR, from those with large extracellular regions, such as the phosphatase CD45. Actin-dependent protrusions would serve to bring the T cell and APC plasma membranes into close proximity, thereby driving molecular segregation. This should occur even in the presence of low numbers of cognate pMHC on the APC surface. (B) The kinetic proofreading model proposes that TCR triggering is based on longer bond lifetimes for strong agonists than weak agonists. The force-dependent catch-bond behavior of the TCR with strong, but not weak, agonist pMHC complexes can enhance bond lifetime for strong agonists, while serving to rupture the slip-bonds formed by TCRs engaging weak or non-agonist pMHC. (C) The serial triggering/serial engagement molecule could benefit from the presence of multiple F-actin interactions with the TCR. Though it may not be force dependent, the association of the TCR with the F-actin network could lead to clustering of the TCR on the plasma membrane, allowing for rapid successive unbinding and rebinding, and serial triggering of multiple TCRs by a single pMHC complex. (D) Several conformational changes that have been described for the TCR may be induced or enhanced by the application of force by the T cell actin cytoskeleton. The first posits a mechanical lever-type action of the TCR under the application of a tangential force. According to this model, bending of the stiff CD3 chains propagates to the intracellular domain and results in signal initiation. The second model suggests that actin associations with the CD3 complex help to pull the CD3 chains away from the inner leaflet of the plasma membrane, thus exposing the ITAMs for phosphorylation and binding of essential regulators such as the kinase ZAP70. The third model is based on catch-bond molecular interactions between TCR and cognate pMHC complexes. According to this variant of the kinetic proofreading model, cytoskeletal force causes a conformational change in the TCR that results in stronger pMHC binding and prolonged or enhanced signaling. 
following simultaneous engagement of multiple TCR molecules $(1,2)$. It is therefore possible that TCR clustering induced by a single pMHC is also induced or stabilized by the F-actin network, thereby leading to enhanced TCR triggering (Figure 3C). In other systems, direct tethering of transmembrane proteins to cortical actin induces nanoclustering (114). The TCR associates with the F-actin network through both ITAM-dependent and -independent mechanisms (115-117). Although the ITAM-dependent mechanism requires phosphorylation by Lck and is therefore likely to take place after initial TCR triggering, the ITAM-independent mechanism is mediated by two RRR sequences in the $\mathrm{CD} 3 \zeta$ chain and causes the constitutive association with F-actin. This association is essential for clustering of the TCR, IS formation, and T cell activation following TCR engagement. Thus, the constitutive and inducible interactions between TCR and F-actin could produce localized increases in TCR concentration, thereby facilitating serial engagement.

\section{Conformational Change and the Mechanical Induction of TCR Triggering}

Recently, the idea that conformational change and mechanosensing may play a critical role in TCR triggering has gained significant traction $(3,12,118)$. Structural studies demonstrate the existence of several conformational changes that can occur upon pMHC binding (119-122). In many cases, however, the documented changes in TCR structure did not propagate away from the pMHC-binding site. Conformational changes in the constant domain, away from the antigen-binding site, were subtle, and it remains unclear if these represent conserved changes found in all triggering interactions. Furthermore, it is unclear how such small changes can propagate to the intracellular portion of the CD3 chains. This brings us to the one key problem faced by models proposing conformational changes initiated in the TCR by pMHC binding alone. Specifically, any conformational change must be present in all TCR/agonist pMHC interactions and absent from TCR/non-agonist pMHC interactions. Given the near limitless variation in the TCR- and pMHC-binding sites, it is hard to imagine that all productive interactions occur with a given binding geometry necessary to initiate the same structural changes. In support of this, activating antibodies can perform their function in the absence of any overt structural change to the TCR structure in solution (123). Further complicating the matter, multiple groups have observed that soluble monomeric pMHC is poorly suited to activating $\mathrm{T}$ cells, even at extremely high concentrations (124-128), despite TCR/pMHC half-lives otherwise associated with TCR triggering in a $2 \mathrm{D}$ environment (109). Finally, as mentioned earlier, simple elongation of the pMHC reduces TCR triggering despite maintaining efficient binding to the TCR, again suggesting that binding-induced conformational change is unlikely to represent a complete TCR triggering mechanism. Interestingly, by incorporating slight modifications to the conformational change model that take into account the cell biology of TCR/pMHC interactions at the IS, one can overcome all of these problems (Figure 3D).

Within the IS, the TCR is dynamically associated with the F-actin network through multiple direct and indirect interactions
(Figure 2) $(6,74,116,117,129,130)$. These interactions allow F-actin-generated force to be applied to the TCR $v$ ia the actin-TCR linkage. Any resistance to this force provided by surface-bound pMHC could then be converted into a conserved conformational change in the TCR. One key result of refocusing the driver of conformational change from molecular interactions occurring at the site of pMHC engagement to mechanical force applied on the TCR is that these changes in protein structure can occur regardless of the specific molecular contacts occurring between the TCR and pMHC. As long as the interaction is of sufficient affinity to stay bound in the presence of force, productive TCR triggering will ensue, thus overcoming the challenge created by the diversity in pMHC/TCR interactions. Additionally, this mechanism does not require that conformational changes occur within the ectodomains of the TCR subunits; it works equally well for changes in ITAM-containing intracellular domains (131).

Several lines of evidence support the existence of a mechanotransduction-based mechanism for TCR triggering. As mentioned earlier, observations that soluble monomeric pMHC cannot initiate efficient TCR triggering pose a particular problem for the conformational change model (124). Interestingly, surface anchoring of monomeric pMHC overcomes this limitation as low numbers of surface-bound monomeric pMHC can initiate TCR triggering $(86,132,133)$. In part, this sensitivity to pMHC and continued signaling is dependent on an intact cytoskeleton, as addition of actin depolymerizing agents causes rapid loss of calcium flux without loss of IS formation $(1,132,134)$. This effect of actin inhibition is specific to $2 \mathrm{D}$ stimulatory settings, since actin depolymerization when the TCR is cross-linked in solution leads to prolonged calcium responses (135). Moreover, inhibition of cytoskeletal dynamics under conditions that retain the actin scaffold also results in a drop in intracellular calcium (2), showing that dynamic actin plays an active role. A likely explanation for these observations is that in the $2 \mathrm{D}$ setting, as opposed to monomer in solution, the dynamic actin filaments can generate force on the pMHC/TCR bond, thereby initiating signaling. Supporting this idea, tangential force applied on the TCR through non-activating antibodies can result in initiation of calcium flux. Strong stimulatory anti-CD $3 €$ antibodies may mimic this force by binding to the side of the complex in a way that induces a bending of the CD3 molecule, in contrast to non-activating antibodies that bind more perpendicularly at the membrane-distal portion of the CD3 complex (136). These data support a model in which force on the TCR/pMHC complex applied tangentially, and not normally, makes the TCR act as a lever, bending and activating the associated CD3 complexes (Figure 3D, model 1) (137). Critically, the actin flow at the IS is radially symmetric and directed toward the center of the IS. Force vector measurements at the IS show that this actin flow results in a similarly directed force applied to the substratum through the TCR $(138,139)$. This force is consistent with the F-actin-driven centralization of TCR microclusters and would apply a tangential force on the TCR/pMHC bond.

Interestingly, an external normal force can also initiate TCR triggering, though whether normal and tangential forces act by the same or different conformational triggering mechanisms is unknown (140). Critically, it was shown that simple contact between the TCR and pMHC probe was insufficient to induce 
signaling. Instead, continuous force was required to maintain calcium flux; signaling stopped and resumed with the cessation and reapplication, respectively, of external force. Consistent with this, the loss of TCR triggering that occurs when the extracellular domain of the pMHC is artificially elongated, usually used as evidence for the kinetic-segregation model, can be overcome through the application of tangential or normal force to the TCR/ pMHC bond. This finding is important in that it suggests that prior findings, interpreted as support for the kinetic-segregation model, can be reevaluated to fit into a coherent theory of TCR triggering based on the application of force on the TCR/pMHC bond. Although these findings strongly suggest the existence of conformational changes induced through the application of normal and/or tangential force, the structural nature of these changes with each type of force is still unclear. This is complicated by the fact that conformational changes under strain are particularly difficult to study, as they are not likely to exist with pMHC binding to purified, soluble, TCR components.

How exactly force is applied to the TCR is an important question. As already mentioned, the TCR can interact both directly and indirectly with the actin cytoskeleton. The direct association of $\mathrm{CD} 3 \zeta$ is mediated by two stretches of basic amino acids, and mutation of these residues results in decreased synapse formation and $\mathrm{T}$ cell activation (116). Interestingly, these same amino acid stretches also mediate binding of the $\mathrm{CD} 3 \zeta$ to the negatively charged inner leaflet of the plasma membrane, limit the phosphorylation of ITAMs $(141,142)$, and are required for synaptic recruitment of CD3 (143). The dual role of the basic stretch suggests a possible competition of binding for the basic residues in the $\mathrm{CD} 3 \zeta$ cytoplasmic domain, with binding to the inner leaflet acting as a negative regulator for activation, and binding to the actin cytoskeleton acting as a positive regulator. It also raises the possibility that following ligand binding, force exerted by the actin cytoskeleton on $\mathrm{CD} 3 \zeta$ may physically disrupt the association of CD3 chains with the plasma membrane, helping to expose the ITAMs for subsequent phosphorylation (Figure 3D, model 2). Similar binding of the CD $\epsilon €$ chain to the plasma membrane also restricts phosphorylation of ITAMs within the $\epsilon$ chain by Lck (144). Though no direct CD3e/F-actin interaction has been discovered, it is known that $\mathrm{CD} 3 €$ can bind directly to Nck following TCR engagement prior to detectable phosphorylation of ITAMs, and the Nck-binding site is exposed following TCR engagement, and independently of TCR signal initiation (131, 145). This interaction is critical for the initiation of TCR triggering at very early steps, since mutating the residues involved in Nck binding or blocking the interaction with cell permeant peptides results in greatly diminished phosphorylation of $\mathrm{CD} 3 \zeta$, CD3e, and Zap70, reduced recruitment of CD3 to the synapse, and inhibition of proliferation and effector function $(146,147)$. Nck is linked to actin polymerization through recruitment and binding of N-WASp and WASp $(148,149)$. Since an N-WASpmediated linkage between actin and p130 Cas has been proposed to cause the force-dependent activation of p130 Cas (150), it is likely that the connection of $\mathrm{CD} 3 €$ to the F-actin network through Nck can transduce a similar force. Therefore, CD3€ ITAM phosphorylation could be regulated by actin-generated force in a way similar to the one proposed for $\mathrm{CD} 3 \zeta$.
An alternate model involving normal force stems from recent work by Liu et al. demonstrating that TCR/pMHC interactions show catch-bond behavior (111). Since many of the theoretical mechanisms for catch-bond formation require an accompanying conformational change (151), this study provides strong circumstantial evidence for the existence of an as-yet undefined conformational change at the site of TCR/pMHC interaction. In the study by Liu et al., a tensile normal force was applied by retraction of an extracellular probe bearing pMHC, though it has been theorized that a similar normal force can be generated internally through the action of the F-actin network (118). In this case, the F-actin flow at the IS would pull on the TCR, inducing a conformational change in the ectodomain that would strengthen the interaction with bound pMHC complexes (Figure 3D, model $3)$. Even if this conformational change does not initiate signaling, it could enhance the probability of TCR triggering, as in the kinetic proofreading model.

\section{Regulation of Integrin Function by Cytoskeletal Forces}

In T cell/APC contacts, integrins are primarily responsible for the adhesive interactions that maintain cell-cell contact $(152,153)$. Each integrin consists of an $\alpha$ and a $\beta$ subunit, paired as shown in Figure 4A. In T cells, integrins are required for firm adhesion to endothelium during diapedesis and for formation of stable $\mathrm{T}$ cell/APC interactions, resulting in $\mathrm{T}$ cell activation or effector function. As such, integrins must function in a variety of extracellular environments, even under the extraordinary strain placed on the integrin-ligand bonds by the shear flow in blood vessels. Furthermore, integrin activation must be tightly regulated to prevent improper lymphocyte function. In general, integrins are regulated at two distinct levels: affinity (the strength of interaction between each individual integrin molecule and its ligand) and valency (integrin density at the cell-cell interface). Both valency and affinity contribute to adhesion (154). Therefore, the overall strength of interaction, or avidity, is a product of valency, affinity, and relative contact area (155). In T cells, intracellular signals emanating from chemokine receptors or the TCR have been shown to increase the activation state of integrins on the cell surface. This "inside out" signaling can result in either changes in valency or affinity, and a large body of work has accumulated defining the relevant biochemical pathways (155-157). Recently, new data have emerged demonstrating the regulation of integrin activation through applied forces (158-160). In the following section, the signaling pathways governing integrin activation at the IS will be covered, with a particular focus on the role of cytoskeletal forces in initiating and sustaining changes in integrin valency and affinity.

The $\alpha \mathrm{L} \beta 2$ (CD11a/CD18) integrin LFA-1 is expressed exclusively in leukocytes and is essential for T-cell trafficking and IS formation. In resting $\mathrm{T}$ cells, LFA-1 is maintained in an inactive, bent conformation with very low ligand-binding capacity (Figure 4D). Signaling through TCR and CD28 results in the activation of the small GTPase Rap1 downstream of PLC $\gamma$, PKC $\theta$, and CrkL (161-164) (Figure 2). Following Rap1 activation, talin is recruited to the IS through the action of RIAM, which links talin to 

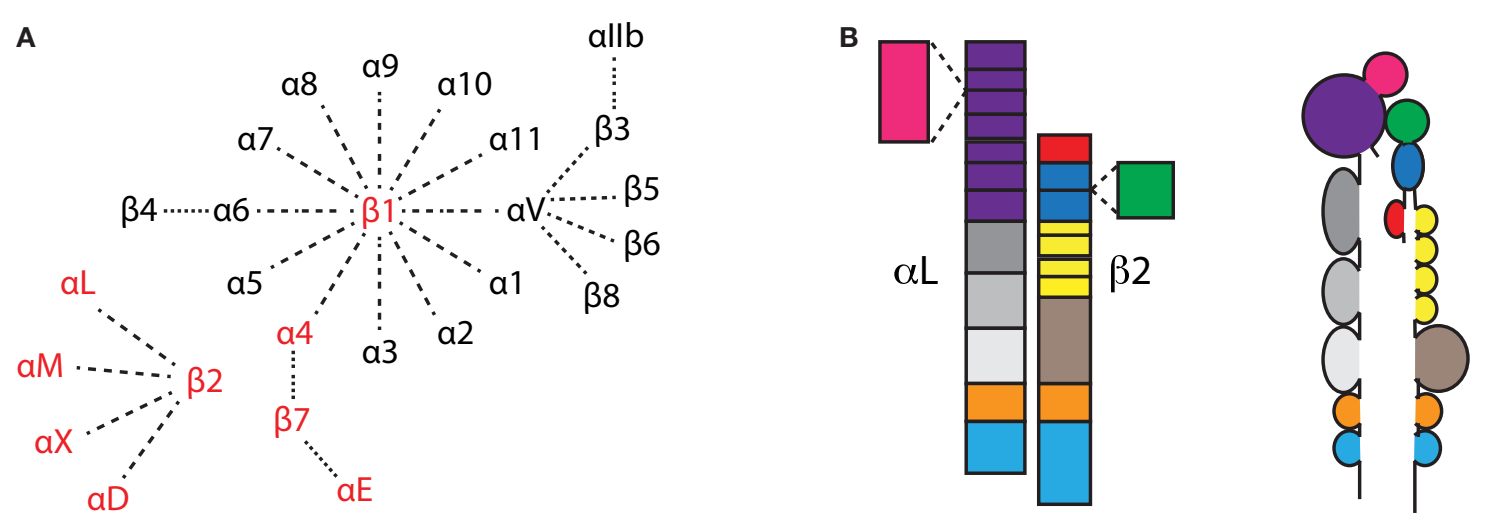

C

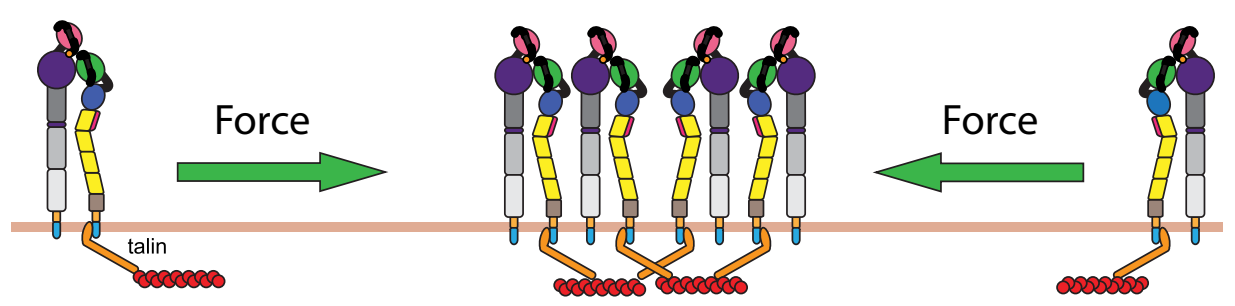

D

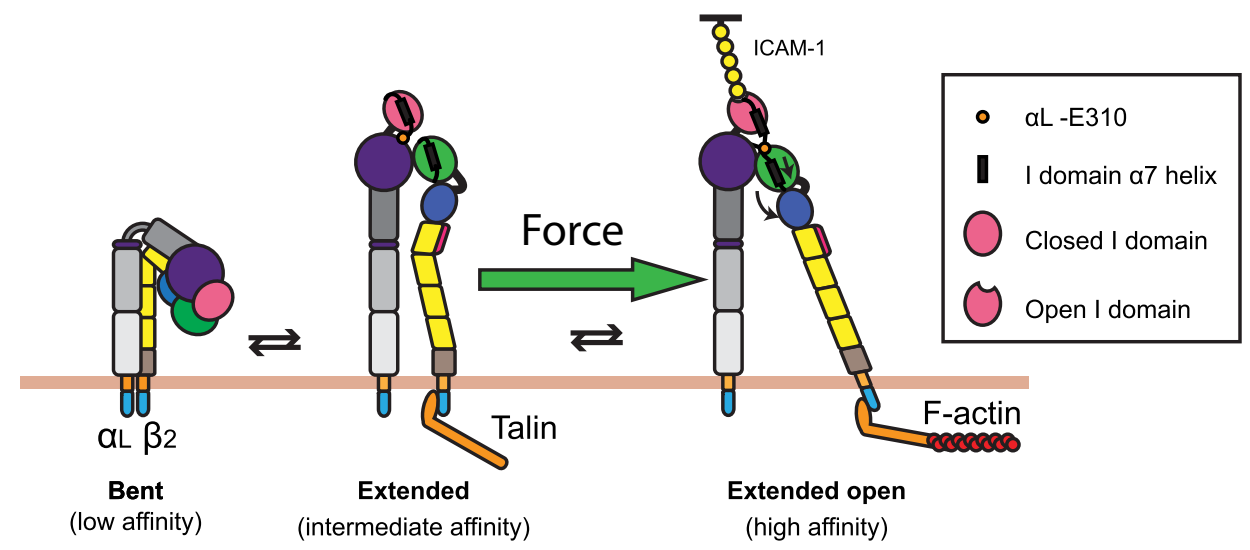

E

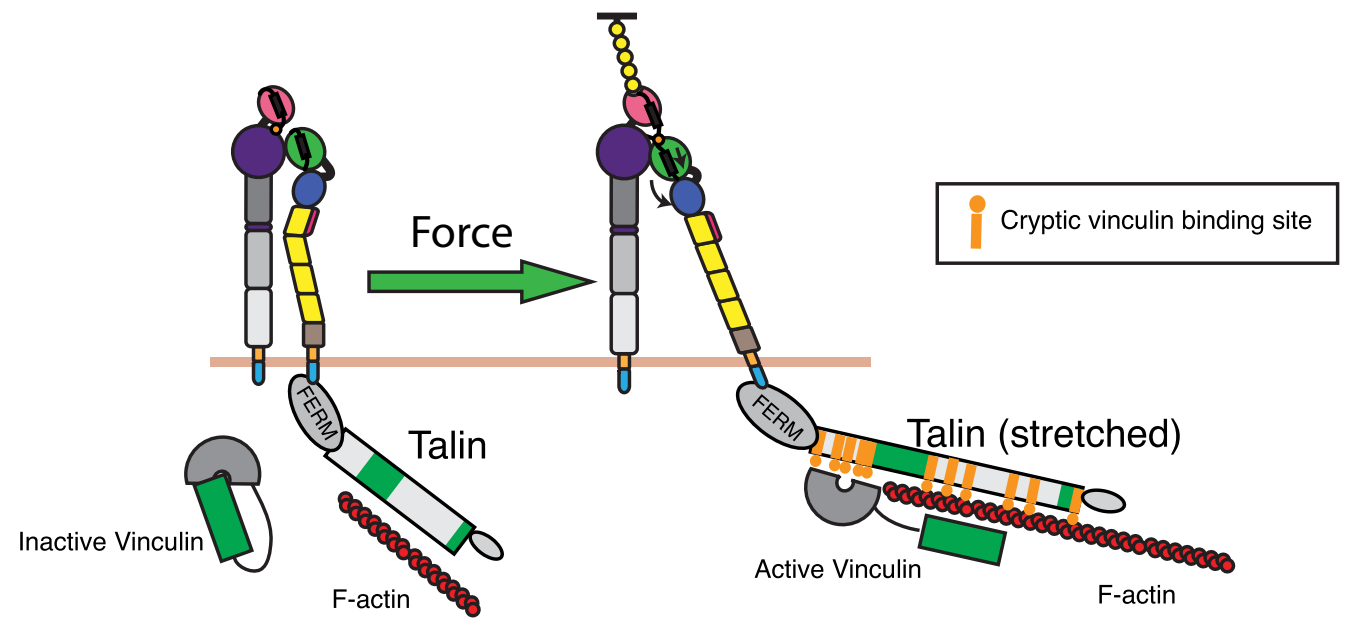

FIGURE 4 | Integrin regulation by cytoskeletal forces 


\section{FIGURE 4 | Continued}

(A) Known $\alpha$ and $\beta$ integrin chains and pairings. Integrin pairs expressed in leukocytes are depicted in red. (B) Domain structure of the integrin LFA-1. The $\alpha$ chain consists of an intracellular tail (cyan), a transmembrane domain (orange), two calf and one thigh domains (gray), and a $\beta$-propeller domain (purple) with an inserted ligand-binding I domain (pink). The $\beta$ chain consists of an intracellular tail (cyan), a transmembrane region (orange), a $\beta$ tail domain (brown), four EGF repeats (yellow), a hybrid domain (blue) with an inserted $\beta$ I domain (green), and a PSI domain (red). (C) Retrograde actin flow drives LFA-1 into the IS from the cell periphery. This increases local concentrations of LFA-1, thereby increasing the valency of the interaction and strengthening cell-cell adhesion. (D) LFA-1 can exist in roughly three conformations: a bent, low affinity conformation; an extended intermediate affinity conformation; and an extended conformation, where the hybrid domain on the $\beta$ chain is swung outward, allowing for downward movement of the $\alpha 7$ helix in the $\beta$ I domain. This downward movement allows the $\beta$ I domain to bind an internal ligand in the $\alpha$ l domain, causing downward movement of the $\alpha$ l domain $\alpha 7$ helix and opening of the ligand-binding site. These changes generate a high affinity, extendedopen conformation. Maintenance of this conformation at the IS is dependent on ongoing actin flow, presumably because connection of the $\beta$ chain intracellular domain to the dynamic F-actin network is enough to drive swing-out of the hybrid domain. The resulting force-dependent increase in affinity would promote and augment changes induced by ligand binding. (E) In addition to regulating LFA-1 affinity for ligand, applied force can also strengthen the connection of LFA-1 to the underlying actin cytoskeleton. Talin, a key protein that links integrins to the actin network, can stretch upon the application of force. This stretching reveals up to 11 cryptic vinculin-binding sites. Vinculin, itself an actin-binding protein, then binds to the exposed sites and reinforces linkage to the F-actin network.

the membrane targeting CAAX domain of activated Rap1 (165). Recruitment of talin to the IS is required for LFA-1 affinity and valency modulation as well as conjugate formation (166). Binding of the talin head domain to the cytoplasmic domain of the integrin $\beta$ chain causes alterations to the $\beta$ transmembrane domain, thereby relieving interactions between the $\alpha$ and $\beta$ chains that maintain the bent conformation. This process allows unfolding of LFA- 1 and the adoption of an intermediate conformation with 10-fold increased affinity for ligand over the bent conformation (167-175). This "switch-blade" like unfolding occurs in the presence of activating antibodies or ligand-mimetic peptides and exposes epitopes that report on integrin activation $(176,177)$. Importantly, overexpression of the talin head domain is enough to result in extension of the majority of LFA-1 molecules on the cell surface, but it does not fully rescue cell adhesion, suggesting that the actin-binding domain of talin is essential for full LFA-1-mediated cell adhesion $(166,178)$. In addition to talin, other proteins, including members of the kindlin family of adaptors, are known to bind to the cytoplasmic domains of integrin $\beta$ chains and link them to the cytoskeleton, further emphasizing that cytoskeletal linkage is essential for proper integrin function $(160,179)$.

The role of the cytoskeleton in mediating changes in LFA-1 valency is not straightforward. Early studies proposed a mechanism whereby cytoskeletal restraints limited the mobility of LFA-1 in resting cells, thus preventing clustering. Upon activation, cytoskeletal restraints were released, allowing the free diffusion and coalescence of LFA-1, thus increasing valency (180-182). In this model, the increased association of high affinity LFA-1 with the cytoskeleton limits the ability to support firm adhesion (183). In support of this idea, low dose Cytochalasin D increases LFA-1 mobility and clustering and increases cell adhesion to ICAM1-coated surfaces. These changes do not induce, and function independently of, changes to integrin affinity and conformational change $(154,184)$. Importantly, later studies demonstrated that the integrin clustering mediated by actin depolymerization only occurs in the presence of ligand, and suggested a trapping mechanism aided by the increased diffusivity of LFA-1 in the absence of the cytoskeleton (184). This would indicate that LFA-1 interaction with the cytoskeleton limits valency and is in contradiction with the finding that talin, the main link between LFA-1 and the cytoskeleton, is required for LFA-1 synaptic accumulation (166). Further complicating the picture is the observation that transport of microclusters containing LFA- 1 and ICAM- 1 at the IS is dependent on an intact actomyosin network $(4,185)$. One of the key confounding factors in this literature is that the studies that identified the actin cytoskeleton as a negative regulator of LFA-1 valency were not carried out within the context of an IS. In an IS setting, actin retrograde flow can actively draw LFA-1 into the IS, increasing the valency of LFA-1/ICAM-1 interactions (Figure 4C).

In addition to the regulation of valency, integrin avidity can be regulated at the level of affinity. Changes in integrin affinity are generally associated with conformational changes (158) (Figure 4D). As previously mentioned, "inside out" regulation of integrin extension mediates the transition from the low affinity to the high affinity conformation. Conformational change from the intermediate to the high affinity state results in a further 100 -fold increase in affinity for ligand and has been proposed to be mediated by forces generated by the $\mathrm{T}$ cell actin cytoskeleton (159, 175). Structural changes associated with integrin activation have been characterized using activating mutations and antibodies (176, 186-188). Typically, integrin activation and ligand binding are associated with a lateral swing-out of the hybrid domain and downward movement of the $\alpha 7$ helix in the $\beta$ I domain. This induces the high affinity conformation of the $\beta \mathrm{I}$ domain and has been shown to occur through a series of conformational intermediates (189). In $\alpha$ I domain-containing integrins such as LFA-1, the activated $\beta I$ domain binds an invariant glutamate residue in the $\mathrm{C}$-linker region between the $\alpha \mathrm{I}$ - and $\beta$-propeller region. This results in downward movement of the $\alpha \mathrm{I}$ domain $\alpha 7$ helix and adoption of the extended open, high affinity, $\alpha$ I domain. Importantly, antibodies that stabilize the extended and extendedopen conformations greatly increase LFA-1's affinity for ligand, resulting in a near 1000-fold dynamic affinity range from the bent to the extended-open conformations $(175,190)$. Furthermore, shortening of the $\mathrm{C}$-linker region to mimic the downward motion exerted by the $\beta$ I domain results in constitutively active LFA-1 (187). Steered molecular dynamic simulations have demonstrated that conversion between different integrin conformations can occur through the application of physical forces. Pulling on the headpiece or on bound ligand can overcome interactions between the hybrid and $\beta$-tail domains that help maintain the bent conformation, resulting in integrin extension. Importantly, forces applied to the headpiece were not sufficient in these simulations to induce the opening of the headpiece or separation of the integrin legs (191). Interestingly, similar simulations have shown that a tensile force applied parallel to the membrane on 
the $\beta$ cytoplasmic tail can be propagated along the $\beta$ chain, resulting in hybrid domain swing-out and affinity modulation (188). Since talin binds to the integrin $\beta$ cytoplasmic domain, any force applied on LFA-1 through talin's linkage to the retrograde actin flow at the IS would result in a similar tensile force, and should mediate integrin affinity maturation (Figure 4E). Intriguingly, it is known that high affinity LFA-1 is more tightly bound to the actin cytoskeleton than intermediate or low affinity LFA-1, supporting the idea that linkage to the underlying cytoskeleton is involved in conformational regulation (192). Our recent work has demonstrated that, indeed, the force provided by retrograde actin flow is critical for maintaining LFA-1 in the high affinity conformation, ligand binding, and clustering of LFA-1 at the IS (193). Thus, connection of LFA-1 to the dynamic actin network provides the force required to initiate integrin recruitment to and clustering within the IS, thereby increasing valency, and also provides the force to induce conformational change to the high affinity state (Figure 4, green arrows).

Consistent with the prediction that force can enhance LFA-1 affinity, integrins engage in catch-bond interactions (194-196). As with other adhesion molecules, such as selectins, integrin bond lifetime increases as tensile normal force is applied, until a threshold known as critical force is reached, where bonds are rapidly ruptured $(151,197)$. Importantly, blocking binding of the $\alpha$ I internal ligand by the open $\beta I$ domain inhibits catch-bond behavior, suggesting that conformational change initiated by hybrid domain swing-out is required to initiate catch-bond interactions. Furthermore, it has been shown that $\alpha 5 \beta 1$ and LFA-1 bond lifetimes are increased following a short, transient, period of high force application. For LFA-1/ICAM-1 interactions, loading and then unloading of applied force stabilizes the integrin/ligand bond, increasing the average bond lifetime from 1.5 to over 35 seconds (198).

So far, we have discussed the mechanosenstive aspects of LFA-1 regulation with a focus on integrin-ligand interactions. Importantly, the connection between the T cell and the APC mediated by the integrin-ligand bond is only as strong as the weakest link in the pathway (199). Whereas catch-bond interactions between integrins and their ligands exhibit increased affinity with the application of force, the links that connect integrins to the cytoskeleton are thought to behave as more conventional slip bonds, where force decreases bond lifetime. Nonetheless, the talin-mediated linkage of LFA-1 to the actin cytoskeleton is regulated by the application of force. Once talin binds to the integrin $\beta$ tail through its head domain and to F-actin through its rod domain, actin-myosin-mediated force pulls on talin. This causes talin to unfold like an uncoiling spring, thereby exposing up to 11 cryptic vinculin-binding sites (200, 201) (Figure 4E). Binding of vinculin to the talin rod domain then allows vinculin to bind to F-actin and enforces the integrin linkage to the actin cytoskeleton (160, 201-204). Although this process is reversible, such that loss of force leads to diminished vinculin binding, vinculin binding can stabilize the unfolded conformation of talin (205). In T cells, vinculin is recruited to the IS and is required for talin recruitment and conjugate formation, suggesting that the destabilized talinF-actin bond is not enough to maintain LFA-1 activation (206). Thus, talin-vinculin binding represents another force-dependent step in the pathway leading to integrin activation, and another mechanism through which cell adhesion can be enhanced by F-actin flow (Figure 4E).

Integrin-mediated outside-in signaling has been mentioned earlier as a driver of multiple pathways of $\mathrm{T}$ cell activation. Importantly, the conformational changes that mediate LFA-1 affinity maturation are also required for outside-in signal initiation. Blocking LFA-1 affinity maturation leads to decreased IL-2 production and T cell proliferation (207). Likewise, inhibition of the separation of the transmembrane domains through addition of an inter-subunit disulfide bond results in the loss of outside-in induced stress fiber formation and cell spreading in $\mathrm{CHO}$ cells (208). Conversely, affinity modulation through the addition of conformational change-inducing antibodies results in the same pattern of outside-in tyrosine phosphorylation as actual ligand binding. This suggests that integrin conformational changes are necessary and sufficient to induce outside-in signaling. Therefore, forces on the integrin-ligand bond that induce and stabilize integrin conformational change are likely to also be required to initiate and sustain outside-in signal transduction.

Given the accumulating evidence that physical force exerted by the actin cytoskeleton drives conformational changes that mediate LFA-1 activation and stabilize this active conformation, we must re-evaluate our understanding of TCR-mediated integrin activation. Under this new paradigm, forces generated by the retrograde flow of the $\mathrm{T}$ cell actin cytoskeleton act as a key component of inside-out signaling and are a critical allosteric regulator of integrin activation at the IS.

\section{Regulation of CD28 Signaling by the F-Actin Network}

As with the TCR and LFA-1, there is strong evidence that F-actin contributes to costimulatory signaling at the IS. Here, we will focus on $\mathrm{CD} 28$, although signaling through CD2 and other costimulatory molecules also involves the actin cytoskeleton (52-55, 209-211). Microclusters of CD28 form concomitantly with TCR microclusters and then segregate into their own domain outside of the cSMAC, but the role of F-actin in the formation and centralization of these microclusters is unknown. Somewhat surprisingly, CD28 microclusters only require the presence of ligand to form and centralize and will do so even in the absence of the CD28 cytoplasmic tail, though differences in the rates were not addressed (212). This suggests that CD28 microcluster formation is primarily the result of kinetic segregation. If so, F-actin dynamics could contribute to this process, as diagrammed in Figure 5. Regardless of the effects of F-actin on CD28 microclusters, several studies indicate that propagation of signals downstream of CD28 is dependent on F-actin dynamics. First, the F-actin-uncapping protein Rltpr, which interacts with CD28, is absolutely required for CD28 signaling. Rltpr-deficient mice mimic the phenotype of CD28 knockout mice, and Rlptr is required for the CD28-mediated focusing of PKC $\theta$ and Carma 1 within the central region of the IS (49). Second, Tan et al. showed in thymocytes that activation of Src kinases by acute inhibition of Csk recapitulates many early signaling events in the TCR signaling pathway, but does not allow elevation of intracellular $\mathrm{Ca}^{2+}$ or ERK phosphorylation (45). Intriguingly, this blockade in 


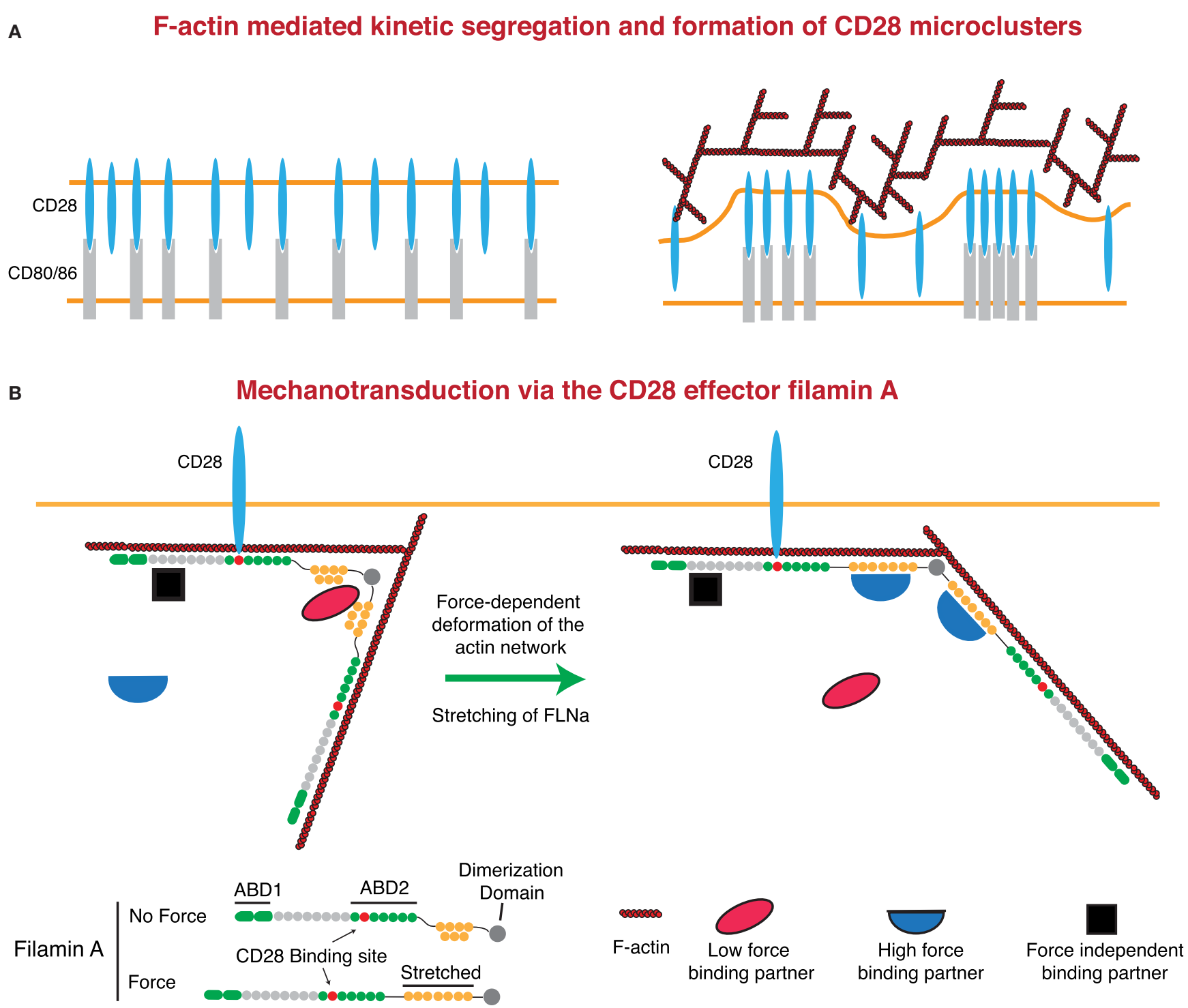

FIGURE 5 | Regulation of CD28 signaling by applied forces. (A) CD28 clustering at the IS may occur in a signaling-independent manner through the kinetic segregation of bound and unbound molecules. Actin polymerization could contribute to this process by generating protrusions that bring the $T$ cell plasma membrane into close proximity with that of the APC. In the case of a receptor and a surface bound ligand, the free receptor would occupy less extracellular space than the bound receptor-ligand pair, such that bound receptors would be forced to cluster within areas of low membrane proximity. (B) Filamin A (FLNa) is a scaffolding protein and an essential CD28 effector that can undergo force-dependent conformational change. Force causes the extension of the second rod domain of filamin A, eliminating binding sites that exist in the relaxed protein, and exposing a different set of binding sites that only exist in the extended protein. Thus, under tension, FLNa can release low force-binding partners and recruit new proteins to the CD28 signaling complex.

signaling could be overcome by perturbing the actin cytoskeleton or by stimulating CD28-mediated F-actin rearrangement. These data support a model in which cortical actin forms a functional barrier between active PLC- $\gamma 1$ and its substrate, and engagement of $\mathrm{CD} 28$ remodels actin architecture to allow signaling to proceed. Finally, it has been shown that costimulatory signaling by CD28 can induce greater force on stimulatory surfaces than TCR triggering alone (presumably through regulation of the F-actin network). This additional force is not applied through CD28 itself. Instead, force is applied through the TCR, at least in the absence of integrin engagement (138). Perhaps CD28 costimulation can lead to greater forces on other mechanosensitive receptors, including integrins. This idea is consistent with the finding that CD80 and CD86 on DCs increase the strength of cell-cell interactions with a responding $\mathrm{T}$ cell (213).

CD28 interacts with the F-actin cross-linking protein filamin A (FLNa) through the PxxPP motif in the CD28 cytoplasmic tail and domains 10-12 of FLNa. FLNa is recruited to the IS in a CD28-dependent manner following TCR stimulation, and CD28 interaction with FLNa is required for T cell costimulation (214). FLNa is a large, rod-like protein that is composed of an $\mathrm{N}$-terminal actin-binding domain and 24 Ig-like domains. Ig-like domains 
1-15 are referred to as Rod 1, while domains 16-23 make up Rod 2 , with the 24th domain allowing for homodimerization. In addition to binding actin, FLNa is a prolific scaffolding protein with over 90 known binding partners, including intracellular signaling molecules, receptors, ion channels, transcription factors, and adhesion proteins $(215,216)$. Critically, many of these interactions can be regulated through the application of either external or internally generated force. Cryptic binding sites in the compact Rod 2 domain are exposed, and binding sites in the normal state are abolished following the application of force. This could occur through stretching of the Rod 2 domain under conditions where the F-actin network is under stress (216-218). This is particularly relevant at the IS, where the robust F-actin flow is likely to apply considerable stress to the network and may represent an important force-dependent aspect of CD28-mediated costimulation (Figure 5). Indeed, the mechanical regulation of FLNabinding partners sets up several potential signaling mechanisms. Molecules that are recruited under force could allow for localized signal activation and signal amplification. Conversely, molecules that are released following force application could act as soluble signaling factors, exerting their function on areas distant from the IS. FLNa has been shown to be important for PKC $\theta$ recruitment to, and NF- $\kappa \mathrm{B}$-inducing kinase (NIK) activation at, the IS. Interestingly, while NIK is constitutively associated with FLNa, interaction with $\mathrm{PKC} \theta$ requires $\mathrm{CD} 3 / \mathrm{CD} 28$ signaling. Thus, it will be interesting to see if FLNa-mediated CD28 recruitment of $\mathrm{PKC} \theta$ is force dependent.

\section{Force-Based Activation of Other Mechanosensitive Molecules at the IS}

The preceding sections address force-induced activation of surface expressed receptors and their ligands, but F-actin-generated forces affect cytoplasmic molecules as well. One prime example is CasL, a lymphocyte-specific member of the Crk-associated substrate (Cas) family of proteins. Members of the Cas family contain a highly conserved Src kinase substrate domain with multiple phosphorylatable YxxP motifs. For the non-hematopoietic isoform p130Cas, it has been shown that these motifs are exposed by mechanical stretching of the protein $(219,220)$. Stretching of p130Cas and exposure/phosphorylation of the Crk-binding site is dependent on integrin binding to an immobilized substrate. In T cells, phosphorylation of CasL allows binding to Crk and the associated GEF C3G, leading to the activation of the small GTPase Rap1. Since Rap1 activation induces the recruitment of talin and the affinity maturation of multiple integrins, it seems likely that CasL functions in a positive feedback loop linking mechanical forces on engaged integrins to additional integrin activation.

Two independent studies have demonstrated that myosin contractility is required for maximal CasL phosphorylation, though in both studies there was significant CasL phosphorylation left at the IS following myosin inhibition (221, 222). Interestingly, phosphorylation of Cas within the substrate domain is largely independent of myosin contractility, but completely dependent on F-actin polymerization (150). It is therefore likely that even in the absence of myosin contractility, continued polymerizationdriven F-actin flow at the IS provides sufficient force to drive stretch-dependent Cas/CasL activation.

\section{Cytoskeletal Forces May Create Signaling Rich and Poor Zones at the IS}

Different mechanosensitive receptors can apply varying amounts of force on their ligands (223), and the maximum amount of force that can be applied is only as strong as the weakest link in the complex that links ligand to receptor and receptor to the actin network (199). Because of this, the force that allows for the greatest signaling for each receptor could be very different depending on the strength of these varying molecular interactions. In terms of the IS, TCR-pMHC catch-bonds can withstand a maximum force of roughly $10 \mathrm{pN}$. Unfolding of domain 20 in the CD28-binding protein FLNa occurs with the application of roughly $15 \mathrm{pN}$ (224), while the integrin-ligand bonds are capable of withstanding maximum force of $30 \mathrm{pN}(111,194)$. Even the linkage of vinculin to the talin rod domains has a maximum force $(\sim 25 \mathrm{pN})$ that can be applied before unbinding occurs, since the talin helices become unstable (225). Since we have shown that the F-actin network slows as it moves toward the center of the IS, peak force is likely to decrease concomitantly [this assumes that force is directly proportional to the rate of F-actin flow, though reality may be more complex (199)]. If so, then signaling from force-resistant molecules would be initiated and sustained in regions of high and moderate F-actin dynamics (i.e., dSMAC and pSMAC regions), while molecular interactions with low force resistance would only occur in areas of moderate F-actin dynamics (i.e., the pSMAC region). This could set up intrinsic areas of maximal signaling for each receptor as microclusters form and traverse the IS. Additionally, since F-actin dynamics are poor or non-existent in the cSMAC, and the cSMAC represents an area of low force generation during the stable phase of IS formation (138), this region should not support force-dependent signaling. In keeping with this model, TCR microclusters retain their phosphorylation in the PSMAC, but become poorly phosphorylated in the CSMAC (77). Thus, the distribution of F-actin-generated forces at the IS may serve both to initiate signaling and to limit ongoing signaling by sweeping microclusters into areas of poor F-actin dynamics. In keeping with this, limiting the centralization of microclusters and maintaining them in the peripheral F-actinrich compartments of the IS enhance microcluster lifetime and signaling (77). Additionally, for molecules that engage in catchbond molecular interactions, the bond strength and half-life may also be regulated across the IS radius, with stronger interactions occurring in areas of higher F-actin-generated force, as long as that force is not above the rupture force. To really understand how changing actin rates and actin-generated forces affect $\mathrm{T}$ cell signaling differentially across the IS, careful measurements of traction forces on different molecules across the IS radius will be required.

\section{THE CONTRIBUTION OF THE DENDRITIC CELL CYTOSKELETON TO T CELL PRIMING}

Although a great deal is known about the mechanisms through which $\mathrm{T}$ cell signaling affects actin dynamics on the $\mathrm{T}$ cell side of the IS, and vice versa, much less is known about the APC side 
of the synapse. The APC has long been assumed to be a passive partner in IS organization, and until recently, little attention has been paid to the possible contribution of the APC cytoskeleton. However, recent evidence indicates that at least for DCs, the F-actin network plays a critical role in regulating IS-associated signaling events leading to $\mathrm{T}$ cell activation.

\section{DCs Form Barriers to Lateral Diffusion and Control Synaptic Patterns}

One area where the DC cytoskeleton is likely to play an active role is in regulating IS formation and structure (226). T cells responding to B cells or stimulatory supported lipid bilayers form the classical mature synapse with a characteristic annular pSMAC and cSMAC pattern $(227,228)$. This shows that in the absence of barriers to ligand mobility, TCR and LFA-1 microclusters will be driven toward the IS center in a T cell autonomous fashion. The $\mathrm{DC} / \mathrm{T}$ cell IS lacks this annular pattern and is instead characterized by multiple patches of protein segregation. Even at late time points, there is no central accumulation of CD3 (229). Therefore, it is highly likely that the DC forms barriers to the free diffusion of $\mathrm{T}$ cell ligands that are either cytoskeletal or topological in nature. Importantly, these two possibilities are not mutually exclusive and the lateral mobility of some proteins could be regulated through linkage to the DC actin cytoskeleton, while others could be restricted by topological barriers. In either case, the DC actin cytoskeleton would play a crucial role in defining and maintaining these diffusive barriers. The existence of barriers at the DC/T cell IS has important implications for the mechanical regulation of signaling. As detailed below, we found that the T cell actin cytoskeleton activates mechanosensitive molecules, such as integrins, by applying force to the receptor-ligand bond, while barriers to diffusion provided by the DC cytoskeleton provide a retentive counter force on the ligand, thereby increasing tension at the molecular level. Through a similar mechanism, regulation of ligand mobility could prevent microcluster centralization and deactivation, thereby enhancing $\mathrm{T}$ cell activation. Just as upregulation of $\mathrm{T}$ cell ligands enhances $\mathrm{T}$ cell priming by mature DCs, control of molecular mobility would serve as a second mechanism through which DCs could modulate their T cell stimulatory capacity.

\section{The DC Cytoskeleton Plays a Critical Role in T Cell Priming}

The DC F-actin network has been observed to polarize toward a cognate $\mathrm{T}$ cell in an MHC-dependent manner (230), and treatment of DCs with actin depolymerizing agents impairs the DCs ability to prime $\mathrm{T}$ cell responses (231). Polarization of the DC actin network is mediated by Rho-family GTPases and is required for proper conjugate formation, IL-2 production, and $\mathrm{T}$ cell proliferation (232-234). Similarly, the ARP2/3 complex activator WASp promotes the maintenance of T cell-DC interactions; WASp-deficient DCs exhibit fewer and shorter-lived contacts with cognate $\mathrm{T}$ cells, and a diminished ability to prime $\mathrm{T}$ cell proliferation $(235,236)$. Although it is clear that the F-actin network on the DC side of the synapse plays a key role in T cell conjugate formation and $\mathrm{T}$ cell activation, how changes in the DC cytoskeleton are regulated, and their role in IS-mediated signal transduction are open questions in the field.

\section{Maturation-Associated Changes in the DC Actin Network}

Following recognition of danger signals through pattern recognition receptors, DCs undergo a maturation process that increases their stimulatory potential as APCs. Maturation is associated with an increase in F-actin content and increased plasma membrane ruffling, as well as major changes in actinregulatory proteins. The resulting cytoskeletal changes alter antigen uptake and migratory behavior and increase the stimulatory potential of DCs by modifying the F-actin network at the DC-IS. Among the actin-regulatory proteins that are upregulated during maturation are the actin bundling protein fascin, which is greatly increased in expression $(237,238)$, the actin-severing protein cofilin, which is activated by dephosphorylation (239), and the actin-binding protein moesin, which is increased both by enhanced expression and phosphorylation-dependent activation (240). Interestingly, there is evidence that fascin and cofilin can work together to remodel the F-actin network (241). Moreover, fascin polarizes to the site of $\mathrm{T}$ cell engagement on DCs (231), and we have observed that T cells preferentially bind to pre-formed moesin-rich regions (240). It is important to point out that in addition to changes in proteins such as fascin, cofilin, and moesin that directly bind to actin filaments, DC maturation is associated with changes in regulatory molecules that control actin dynamics. For example, the activation of the Rho-family GTPase CDC42 is diminished during DC maturation (242). Similarly, the semaphorin receptor plexin-A1 is upregulated during maturation and is recruited to the DC-IS, where it mediates Rho activation, F-actin polarization, and $\mathrm{T}$ cell activation $(234,243)$. Going forward, it will be important to define how these changes in cytoskeletal proteins and their regulators impact DC-IS function. Likely mechanisms include physical reorganization of the DC membrane and generation of cytoskeletal tethers or corrals that limit the lateral mobility of $\mathrm{T}$ cell ligands.

\section{Regulated Mobility of T Cell Ligands on the DC Surface}

Consistent with the idea that activation of T cell surface receptors is force dependent, in vitro analysis shows that modulation of ligand mobility can influence T cell activation (244). Though comparatively few studies have addressed ligand mobility on the DC surface, there is already evidence that ligand mobility is regulated in ways that are important for $\mathrm{T}$ cell priming.

\section{Control of MHC Lateral Mobility}

The strongest evidence that ligand mobility is important for TCR triggering comes from studies in which diffusion of an $\alpha \mathrm{CD} 3$ antibody in stimulatory bilayers is limited by a physical barrier. Under these conditions, TCR microclusters are trapped in the periphery of the IS, resulting in increased microcluster phosphorylation and 
cellular activation (77). Interestingly, limiting the forward mobility of TCR microclusters causes local deformation of the F-actin network $(6,74,245)$, suggesting that molecular forces between the TCR and the viscoelastic actin network are increased.

Though MHC class II lateral mobility is not constrained by the F-actin network in B cells or DCs $(57,240)$, the lateral mobility of MHC class I is restricted by the actin cytoskeleton (246-248). It is worth noting that many of the studies documenting TCR catch-bonds were done using the OTI or 2C CD8 TCR transgenic models, suggesting the possibility that TCR mechanotransduction and control of MHC lateral mobility may be more important in MHCI/TCR than MHCII/TCR interactions. It will be interesting to examine the lateral mobility of MHCI in professional APCs and to ask if the control of MHCI lateral mobility correlates with TCR triggering.

\section{Control of Integrin Ligand Lateral Mobility}

As mechanosenstive proteins, integrins respond to the physical properties of their ligand-binding environment. In fact, integrin-mediated cell spreading does not occur unless the ligand can withstand roughly $40 \mathrm{pN}$ of applied force (223). In line with this idea, stiffness of the extracellular matrix correlates with outside in signaling (249), and surface immobilization of ICAM-1 is required for TCR-induced LFA-1 conformational change $(193,250)$. Importantly, the lateral mobility of ICAM-1 can have dramatic effects on immune cell function. In particular, NK cells adhere firmly to target cells in which ICAM-1 lateral mobility is low, and increasing ICAM-1 mobility decreases the efficiency of conjugate formation and lytic granule polarization (251). This suggests that restriction of the lateral mobility of integrin ligands increases tension on the ICAM-1/LFA-1 bond. In endothelial cells, members of the actinin and ERM family of actin-binding proteins limit the lateral mobility of ICAM-1 through interactions with a concerted polybasic region on the ICAM-1 cytoplasmic tail. Importantly, the constrained lateral mobility of ICAM-1 greatly increases the efficiency of T cell diapedesis, suggesting that this is a critical determining factor for LFA-1 adhesiveness $(252,253)$. We have recently shown that during DC maturation, ICAM-1 undergoes a specific decrease in lateral mobility mediated by interactions with moesin and $\alpha$-actinin, which are upregulated and activated in response to inflammatory stimuli (240). This decrease in ICAM-1 lateral mobility enhances conjugate formation and LFA-1 affinity maturation, and ultimately contributes to $\mathrm{T}$ cell priming. This evidence indicates that DC maturation is associated with biophysical changes that constrain ligand mobility and promote mechanical integrin activation.

\section{Control of CD80/86 Lateral Mobility}

Constrained lateral mobility of the CD28 ligands CD80 and CD86 on the APC surface may also be important for APC function. Consistent with this idea, the cytoplasmic tails of CD80 and CD86 are essential for their costimulatory activity and mediate the separation of CD28 microclusters from TCR microclusters (254). These tails contain a highly conserved poly-basic motif that mediates protein clustering and cytoskeletal interactions $(255,256)$. This motif resembles known ERM-binding sites in other proteins, including ICAM-1 $(253,257)$. Given the importance of F-actin linkage and reorganization to CD28 function, it will be interesting to see if DCs can modulate costimulatory signals by regulating the lateral mobility of CD80 and 86 .

\section{T Cells and DCs Coordinately Regulate the Activation of LFA-1 at the IS}

Although there is increasing evidence that the TCR, CD28, and integrins can be activated by application of external forces on individual receptors, it is critically important to know if the molecular forces generated internally at the IS can drive these same activation pathways. We have recently shown that $\mathrm{T}$ cell actin retrograde flow drives conformational change of the integrin LFA-1 into the high affinity form, as well as its accumulation and organization at the IS (193). In a reciprocal process, DCs actively limit ICAM-1 lateral mobility on the plasma membrane through upregulation of the proteins moesin and $\alpha$-actinin- 1 (240). The limitation on ICAM-1 lateral mobility opposes the forces applied by the $\mathrm{T}$ cell actin cytoskeleton, thus enhancing tension and promoting LFA-1 affinity maturation, $T$ cell adhesion, and priming. Thus, the F-actin networks in the T cell and the interacting DC work in concert to efficiently activate the integrin LFA-1. Interestingly, coordinated regulation of force application on LFA-1 and constrained ICAM-1/ligand lateral mobility is also at play during $\mathrm{T}$ cell migration on and diapedesis through inflamed endothelium $(253,258,259)$. The theme that appears is that $\mathrm{T}$ cell adhesion to either APCs or endothelial cells, whether that is brought on by antigen recognition or exposure to chemokine, involves both a concerted change in the $\mathrm{T}$ cell and a reciprocal change in the interacting partner. Thus, for mechanosensitive molecules involved in T cell function, the physical properties of the ligand on the surface of interacting cells must be considered along with the forces applied to the receptor itself.

\section{FUTURE DIRECTIONS FOR BASIC AND TRANSLATIONAL RESEARCH}

Our understanding of the mechanobiology associated with signaling events at the IS is in its infancy. In particular, we lack concrete information on how the relevant forces are generated at the IS, which molecules act as true mechanosensors, and how the function of these molecules is coordinated to tune the immune response. Pioneering studies using biophysical approaches, such as modulation of substrate stiffness, physical manipulation using micropipettes, and traction force measurements, have all been informative $(81,138,260)$, and there is much work yet to do in this arena.

To relate these biophysical measurements to T cell signaling, we also need to develop additional probes for protein conformation and activation state. For example, antibodies specific for integrin activation intermediates have been quite valuable $(175,193)$, as have antibodies that detect stretching of Cas $(150,222)$. Conformational probes for integrins and Cas family members have been successful because these proteins undergo large scale, concerted, changes as part of their 
regulated function. Given the paucity of robust conformational changes that are detectible in the ectodomains of the TCR, it is unsurprising that similar reagents do not exist for the study of TCR mechanosensing. One conformation-specific antibody has been reported for the TCR, though this epitope is exposed upon pMHC binding even in force-free conditions (131). Building upon work showing that agonist mAbs bind to the membrane-distal CD3e lobe and exert torque on the CD3 complex (136), it may be possible to ask if cytoskeletal forces on TCRs engaged to pMHC have a similar effect by measuring changes in binding of anti-CD $3 €$ Fabs in the presence or absence of F-actin dynamics. In any case, it seems likely that analysis of TCR force sensing will continue to be challenging, and that novel tools that detect changes transmitted across the cell membrane will be needed.

One caveat to the use of conformation-specific antibodies is that they often induce or stabilize the conformations they detect. This considerably limits their use, especially in live cell experiments. Thus, future studies are likely to require fluorescent tension biosensors for live cell microscopy similar to those that have been used to detect force on vinculin (261). This technology is evolving rapidly $(262,263)$. FRET-based biosensors have already been used to detect activation of VLA-4 in migrating T cells (263), and similar biosensors have been used to create integrin ligands that register force applied by spreading cells $(264,265)$. Another ligand-based approach involves a tension gauge tether consisting of a piece of double stranded DNA attached to an integrin ligand on one strand and to the substratum on the other such that the DNA strands separate with applied force, which can be varied over a range of 12-56 pN (223). Related ligand-based force sensors could be extremely useful in measuring the forces applied to specific receptor-ligand pairs, and the effects of cytoskeletal perturbations on these forces.

As a closing note, it is worth considering how new knowledge about the mechanobiology of $\mathrm{T}$ cell signaling could influence immunotherapy. Recent clinical successes have generated great interest in T cell-based immunotherapies for cancer and infection $(266,267)$. Although many approaches exist for adoptive $\mathrm{T}$ cell therapy, a common first step involves the ex vivo expansion of $\mathrm{T}$ cell subsets, typically through the use of stimulatory beads.

\section{REFERENCES}

1. Varma R, Campi G, Yokosuka T, Saito T, Dustin ML. T cell receptor-proximal signals are sustained in peripheral microclusters and terminated in the central supramolecular activation cluster. Immunity (2006) 25(1):117-27. doi:10.1016/j.immuni.2006.04.010

2. Babich A, Li S, O'Connor RS, Milone MC, Freedman BD, Burkhardt JK. F-actin polymerization and retrograde flow drive sustained PLCgammal signaling during T cell activation. J Cell Biol (2012) 197(6):775-87. doi:10.1083/ jcb.201201018

3. Chen W, Zhu C. Mechanical regulation of T-cell functions. Immunol Rev (2013) 256(1):160-76. doi:10.1111/imr.12122

4. Yi J, Wu XS, Crites T, Hammer JA III. Actin retrograde flow and actomyosin II arc contraction drive receptor cluster dynamics at the immunological synapse in Jurkat T cells. Mol Biol Cell (2012) 23(5):834-52. doi:10.1091/ mbc.E11-08-0731
Much thought has gone into optimizing the antibody cocktails used for bead coating, but relatively little attention has been paid to their physical properties. Yet, these properties are likely to be highly significant. For example, most stimulatory magnetic beads commercially available for $\mathrm{T}$ cell activation are $\sim 4 \mu \mathrm{m}$ in diameter; yet, human peripheral blood T cells engaging APCs readily spread to a diameter of $12 \mu \mathrm{m}$ and resting blasts can spread to over $20 \mu \mathrm{m}$. A bead that is not large enough to induce robust spreading is not likely to induce the symmetric actin flow associated with mechanical signaling. Thus, beads with a larger surface area may enhance $\mathrm{T}$ cell activation and expansion. Another key parameter is the rigidity of the stimulatory surface. Human T cells reportedly respond better on softer surfaces, with increased IL-2 secretion, proliferation, and effector function increasing upon decreased cell surface rigidity (81). Interestingly, the substrate rigidity range used in this study was $100-1000 \mathrm{kPa}$, several orders of magnitude above physiological values for soft lymphoid tissues. Further research aimed at optimizing surface area and rigidity may prove valuable in creating artificial APCs for clinical applications.

\section{AUTHOR CONTRIBUTIONS}

WC and JB reviewed and interpreted the literature, drafted and revised the manuscript, and approved the final version for publication. They both agree to be accountable for all aspects of the work in ensuring that questions related to the accuracy or integrity of any part of the work are appropriately investigated and resolved.

\section{ACKNOWLEDGMENTS}

The authors thank members of the Burkhardt lab for helpful conversations, and Drs. Nathan Roy and Daniel Blumenthal for critical reading of the manuscript.

\section{FUNDING}

This work was supported by NIH grants R01AI065644, R01 HL128551, and R01GM104867.

5. Ilani T, Vasiliver-Shamis G, Vardhana S, Bretscher A, Dustin ML. T cell antigen receptor signaling and immunological synapse stability require myosin IIA. Nat Immunol (2009) 10(5):531-9. doi:10.1038/ni.1723

6. Smoligovets AA, Smith AW, Groves JT. Ratiometric imaging of the T-cell actin cytoskeleton reveals the nature of receptor-induced cytoskeletal enrichment. Biophys J (2013) 105(3):L11-3. doi:10.1016/j.bpj.2013.06.031

7. Kumari S, Depoil D, Martinelli R, Judokusumo E, Carmona G, Gertler FB, et al. Actin foci facilitate activation of the phospholipase C-gamma in primary T lymphocytes via the WASP pathway. Elife (2015) 4. doi:10.7554/eLife.04953

8. Sage PT, Varghese LM, Martinelli R, Sciuto TE, Kamei M, Dvorak AM, et al. Antigen recognition is facilitated by invadosome-like protrusions formed by memory/effector T cells. J Immunol (2012) 188(8):3686-99. doi:10.4049/ jimmunol.1102594

9. Carman CV, Sage PT, Sciuto TE, de la Fuente MA, Geha RS, Ochs HD, et al. Transcellular diapedesis is initiated by invasive podosomes. Immunity (2007) 26(6):784-97. doi:10.1016/j.immuni.2007.04.015 
10. Billadeau DD, Nolz JC, Gomez TS. Regulation of T-cell activation by the cytoskeleton. Nat Rev Immunol (2007) 7(2):131-43. doi:10.1038/nri2021

11. Burkhardt JK, Carrizosa E, Shaffer MH. The actin cytoskeleton in T cell activation. Апnu Rev Immunol (2008) 26:233-59. doi:10.1146/annurev. immunol.26.021607.090347

12. Kumari S, Curado S, Mayya V, Dustin ML. T cell antigen receptor activation and actin cytoskeleton remodeling. Biochim Biophys Acta (2014) 1838(2):546-56. doi:10.1016/j.bbamem.2013.05.004

13. Becart S, Altman A. SWAP-70-like adapter of T cells: a novel Lck-regulated guanine nucleotide exchange factor coordinating actin cytoskeleton reorganization and Ca2+ signaling in T cells. Immunol Rev (2009) 232(1):319-33. doi:10.1111/j.1600-065X.2009.00839.x

14. Ku GM, Yablonski D, Manser E, Lim L, Weiss A. A PAK1-PIX-PKL complex is activated by the T-cell receptor independent of Nck, Slp-76 and LAT. EMBO J (2001) 20(3):457-65. doi:10.1093/emboj/20.3.457

15. Missy K, Hu B, Schilling K, Harenberg A, Sakk V, Kuchenbecker K, et al. AlphaPIX Rho GTPase guanine nucleotide exchange factor regulates lymphocyte functions and antigen receptor signaling. Mol Cell Biol (2008) 28(11):3776-89. doi:10.1128/MCB.00507-07

16. Gomez TS, McCarney SD, Carrizosa E, Labno CM, Comiskey EO, Nolz JC, et al. HS1 functions as an essential actin-regulatory adaptor protein at the immune synapse. Immunity (2006) 24(6):741-52. doi:10.1016/j. immuni.2006.03.022

17. Nolz JC, Gomez TS, Zhu P, Li S, Medeiros RB, Shimizu Y, et al. The WAVE2 complex regulates actin cytoskeletal reorganization and CRAC-mediated calcium entry during $\mathrm{T}$ cell activation. Curr Biol (2006) 16(1):24-34. doi:10.1016/j.cub.2005.11.036

18. Zhang J, Shehabeldin A, da Cruz LA, Butler J, Somani AK, McGavin M, et al. Antigen receptor-induced activation and cytoskeletal rearrangement are impaired in Wiskott-Aldrich syndrome protein-deficient lymphocytes. J Exp Med (1999) 190(9):1329-42. doi:10.1084/jem.190.9.1329

19. Pauker MH, Reicher B, Joseph N, Wortzel I, Jakubowicz S, Noy E, et al. WASp family verprolin-homologous protein-2 (WAVE2) and Wiskott-Aldrich syndrome protein (WASp) engage in distinct downstream signaling interactions at the T cell antigen receptor site. J Biol Chem (2014) 289(50):34503-19. doi:10.1074/jbc.M114.591685

20. Cannon JL, Burkhardt JK. Differential roles for Wiskott-Aldrich syndrome protein in immune synapse formation and IL-2 production. JImmunol (2004) 173(3):1658-62. doi:10.4049/jimmunol.173.3.1658

21. Dovas A, Gevrey JC, Grossi A, Park H, Abou-Kheir W, Cox D. Regulation of podosome dynamics by WASp phosphorylation: implication in matrix degradation and chemotaxis in macrophages. JCell Sci (2009) 122(Pt 21):3873-82. doi:10.1242/jcs. 051755

22. Dehring DA, Clarke F, Ricart BG, Huang Y, Gomez TS, Williamson EK, et al. Hematopoietic lineage cell-specific protein 1 functions in concert with the Wiskott-Aldrich syndrome protein to promote podosome array organization and chemotaxis in dendritic cells. J Immunol (2011) 186(8):4805-18. doi:10.4049/jimmunol.1003102

23. Sims TN, Dustin ML. The immunological synapse: integrins take the stage. Immunol Rev (2002) 186:100-17. doi:10.1034/j.1600-065X.2002.18610.x

24. Perez OD, Mitchell D, Jager GC, South S, Murriel C, McBride J, et al. Leukocyte functional antigen 1 lowers $\mathrm{T}$ cell activation thresholds and signaling through cytohesin-1 and Jun-activating binding protein 1. Nat Immunol (2003) 4(11):1083-92. doi:10.1038/ni984

25. Li D, Molldrem JJ, Ma Q. LFA-1 regulates CD8+ T cell activation via T cell receptor-mediated and LFA-1-mediated Erk1/2 signal pathways. J Biol Chem (2009) 284(31):21001-10. doi:10.1074/jbc.M109.002865

26. Tabassam FH, Umehara H, Huang JY, Gouda S, Kono T, Okazaki T, et al. Beta2-integrin, LFA-1, and TCR/CD3 synergistically induce tyrosine phosphorylation of focal adhesion kinase (pp125(FAK)) in PHA-activated T cells. Cell Immunol (1999) 193(2):179-84. doi:10.1006/cimm.1999.1472

27. Baker RG, Hsu CJ, Lee D, Jordan MS, Maltzman JS, Hammer DA, et al. The adapter protein SLP-76 mediates "outside-in" integrin signaling and function in T cells. Mol Cell Biol (2009) 29(20):5578-89. doi:10.1128/ MCB.00283-09

28. Suzuki J, Yamasaki S, Wu J, Koretzky GA, Saito T. The actin cloud induced by LFA-1-mediated outside-in signals lowers the threshold for T-cell activation. Blood (2007) 109(1):168-75. doi:10.1182/blood-2005-12-020164
29. Wang H, Wei B, Bismuth G, Rudd CE. SLP-76-ADAP adaptor module regulates LFA-1 mediated costimulation and T cell motility. Proc Natl Acad Sci U $S$ A (2009) 106(30):12436-41. doi:10.1073/pnas.0900510106

30. Sanchez-Martin L, Sanchez-Sanchez N, Gutierrez-Lopez MD, Rojo AI, Vicente-Manzanares M, Perez-Alvarez MJ, et al. Signaling through the leukocyte integrin LFA-1 in T cells induces a transient activation of Rac-1 that is regulated by Vav and PI3K/Akt-1. J Biol Chem (2004) 279(16):16194-205. doi:10.1074/jbc.M400905200

31. Nurmi SM, Autero M, Raunio AK, Gahmberg CG, Fagerholm SC. Phosphorylation of the LFA-1 integrin beta2-chain on Thr-758 leads to adhesion, Rac-1/Cdc42 activation, and stimulation of CD69 expression in human T cells. J Biol Chem (2007) 282(2):968-75. doi:10.1074/jbc.M608524200

32. Mace EM, Zhang J, Siminovitch KA, Takei F. Elucidation of the integrin LFA-1-mediated signaling pathway of actin polarization in natural killer cells. Blood (2010) 116(8):1272-9. doi:10.1182/blood-2009-12-261487

33. DeMali KA, Barlow CA, Burridge K. Recruitment of the Arp $2 / 3$ complex to vinculin: coupling membrane protrusion to matrix adhesion. JCell Biol (2002) 159(5):881-91. doi:10.1083/jcb.200206043

34. Chorev DS, Moscovitz O, Geiger B, Sharon M. Regulation of focal adhesion formation by a vinculin-Arp2/3 hybrid complex. Nat Commun (2014) 5:3758. doi:10.1038/ncomms4758

35. Nguyen K, Sylvain NR, Bunnell SC. T cell costimulation via the integrin VLA-4 inhibits the actin-dependent centralization of signaling microclusters containing the adaptor SLP-76. Immunity (2008) 28(6):810-21. doi:10.1016/j. immuni.2008.04.019

36. Thievessen I, Thompson PM, Berlemont S, Plevock KM, Plotnikov SV, Zemljic-Harpf A, et al. Vinculin-actin interaction couples actin retrograde flow to focal adhesions, but is dispensable for focal adhesion growth. J Cell Biol (2013) 202(1):163-77. doi:10.1083/jcb.201303129

37. Croft M, Dubey C. Accessory molecule and costimulation requirements for CD4 T cell response. Crit Rev Immunol (1997) 17(1):89-118. doi:10.1615/ CritRevImmunol.v17.i1.40

38. Boomer JS, Green JM. An enigmatic tail of CD28 signaling. Cold Spring Harbor Perspect Biol (2010) 2(8):a002436. doi:10.1101/cshperspect.a002436

39. Isakov N, Altman A. PKC-theta-mediated signal delivery from the TCR/ CD28 surface receptors. Front Immunol (2012) 3:273. doi:10.3389/ fimmu.2012.00273

40. Chen L, Flies DB. Molecular mechanisms of T cell co-stimulation and co-inhibition. Nat Rev Immunol (2013) 13(4):227-42. doi:10.1038/nri3405

41. Yokosuka $\mathrm{T}$, Saito $\mathrm{T}$. Dynamic regulation of T-cell costimulation through TCR-CD28 microclusters. Immunol Rev (2009) 229(1):27-40. doi:10.1111/j.1600-065X.2009.00779.x

42. Rudd CE, Raab M. Independent CD28 signaling via VAV and SLP-76: a model for in trans costimulation. Immunol Rev (2003) 192:32-41. doi:10.1034/j.1600-065X.2003.00005.x

43. Raab M, Pfister S, Rudd CE. CD28 signaling via VAV/SLP-76 adaptors: regulation of cytokine transcription independent of TCR ligation. Immunity (2001) 15(6):921-33. doi:10.1016/S1074-7613(01)00248-5

44. Dennehy KM, Elias F, Na SY, Fischer KD, Hunig T, Luhder F. Mitogenic CD28 signals require the exchange factor Vav1 to enhance TCR signaling at the SLP-76-Vav-Itk signalosome. JImmunol (2007) 178(3):1363-71. doi:10.4049/jimmunol.178.3.1363

45. Tan YX, Manz BN, Freedman TS, Zhang C, Shokat KM, Weiss A. Inhibition of the kinase Csk in thymocytes reveals a requirement for actin remodeling in the initiation of full TCR signaling. Nat Immunol (2014) 15(2):186-94. doi:10.1038/ni.2772

46. Salazar-Fontana LI, Barr V, Samelson LE, Bierer BE. CD28 engagement promotes actin polymerization through the activation of the small Rho GTPase Cdc42 in human T cells. J Immunol (2003) 171(5):2225-32. doi:10.4049/ jimmunol.171.5.2225

47. Serrano-Pertierra E, Cernuda-Morollon E, Lopez-Larrea C. NKG2D- and CD28-mediated costimulation regulate CD8+ T cell chemotaxis through different mechanisms: the role of Cdc42/N-WASp. JLeukoc Biol (2014) 95(3):487-95. doi:10.1189/jlb.0613316

48. Carlsson AE. Stimulation of actin polymerization by filament severing. Biophys J (2006) 90(2):413-22. doi:10.1529/biophysj.105.069765

49. Liang Y, Cucchetti M, Roncagalli R, Yokosuka T, Malzac A, Bertosio E, et al. The lymphoid lineage-specific actin-uncapping protein Rltpr is essential 
for costimulation via CD28 and the development of regulatory T cells. Nat Immunol (2013) 14(8):858-66. doi:10.1038/ni.2634

50. Bachmann MF, Barner M, Kopf M. CD2 sets quantitative thresholds in T cell activation. J Exp Med (1999) 190(10):1383-92. doi:10.1084/jem.190.10.1383

51. Kaizuka Y, Douglass AD, Vardhana S, Dustin ML, Vale RD. The coreceptor $\mathrm{CD} 2$ uses plasma membrane microdomains to transduce signals in $\mathrm{T}$ cells. J Cell Biol (2009) 185(3):521-34. doi:10.1083/jcb.200809136

52. Hutchings NJ, Clarkson N, Chalkley R, Barclay AN, Brown MH. Linking the $\mathrm{T}$ cell surface protein $\mathrm{CD} 2$ to the actin-capping protein CAPZ via CMS and CIN85. J Biol Chem (2003) 278(25):22396-403. doi:10.1074/jbc.M302540200

53. Tibaldi EV, Reinherz EL. CD2BP3, CIN85 and the structurally related adaptor protein CMS bind to the same CD2 cytoplasmic segment, but elicit divergent functional activities. Int Immunol (2003) 15(3):313-29. doi:10.1093/intimm/ dxg032

54. Zhao J, Bruck S, Cemerski S, Zhang L, Butler B, Dani A, et al. CD2AP links cortactin and capping protein at the cell periphery to facilitate formation of lamellipodia. Mol Cell Biol (2013) 33(1):38-47. doi:10.1128/MCB.00734-12

55. Badour K, Zhang J, Shi F, McGavin MK, Rampersad V, Hardy LA, et al. The Wiskott-Aldrich syndrome protein acts downstream of CD2 and the CD2AP and PSTPIP1 adaptors to promote formation of the immunological synapse. Immunity (2003) 18(1):141-54. doi:10.1016/S1074-7613(02)00516-2

56. Kirsch KH, Georgescu MM, Ishimaru S, Hanafusa H. CMS: an adapter molecule involved in cytoskeletal rearrangements. Proc Natl Acad Sci U S A (1999) 96(11):6211-6. doi:10.1073/pnas.96.11.6211

57. Treanor B, Depoil D, Gonzalez-Granja A, Barral P, Weber M, Dushek O, et al. The membrane skeleton controls diffusion dynamics and signaling through the B cell receptor. Immunity (2010) 32(2):187-99. doi:10.1016/j. immuni.2009.12.005

58. Kumar R, Ferez M, Swamy M, Arechaga I, Rejas MT, Valpuesta JM, et al. Increased sensitivity of antigen-experienced $\mathrm{T}$ cells through the enrichment of oligomeric T cell receptor complexes. Immunity (2011) 35(3):375-87. doi:10.1016/j.immuni.2011.08.010

59. Lillemeier BF, Mortelmaier MA, Forstner MB, Huppa JB, Groves JT, Davis MM. TCR and Lat are expressed on separate protein islands on T cell membranes and concatenate during activation. Nat Immunol (2010) 11(1):90-6. doi:10.1038/ni.1832

60. Sherman E, Barr V, Manley S, Patterson G, Balagopalan L, Akpan I, et al. Functional nanoscale organization of signaling molecules downstream of the $\mathrm{T}$ cell antigen receptor. Immunity (2011) 35(5):705-20. doi:10.1016/j. immuni.2011.10.004

61. Treanor B, Depoil D, Bruckbauer A, Batista FD. Dynamic cortical actin remodeling by ERM proteins controls BCR microcluster organization and integrity. J Exp Med (2011) 208(5):1055-68. doi:10.1084/jem.20101125

62. Faure S, Salazar-Fontana LI, Semichon M, Tybulewicz VL, Bismuth G, Trautmann A, et al. ERM proteins regulate cytoskeleton relaxation promoting T cell-APC conjugation. Nat Immunol (2004) 5(3):272-9. doi:10.1038/ ni1039

63. Lammermann T, Bader BL, Monkley SJ, Worbs T, Wedlich-Soldner R, Hirsch $\mathrm{K}$, et al. Rapid leukocyte migration by integrin-independent flowing and squeezing. Nature (2008) 453(7191):51-5. doi:10.1038/nature06887

64. Morin NA, Oakes PW, Hyun YM, Lee D, Chin YE, King MR, et al. Nonmuscle myosin heavy chain IIA mediates integrin LFA-1 de-adhesion during T lymphocyte migration. JExp Med (2008) 205(1):195-205. doi:10.1084/ jem. 20071543

65. Sanchez-Madrid F, Serrador JM. Bringing up the rear: defining the roles of the uropod. Nat Rev Mol Cell Biol (2009) 10(5):353-9. doi:10.1038/nrm2680

66. Dustin ML. Modular design of immunological synapses and kinapses. Cold Spring Harbor Perspect Biol (2009) 1(1):a002873. doi:10.1101/cshperspect. a002873

67. Dustin ML. Hunter to gatherer and back: immunological synapses and kinapses as variations on the theme of amoeboid locomotion. Annu Rev Cell Dev Biol (2008) 24:577-96. doi:10.1146/annurev.cellbio.24.110707.175226

68. Sims TN, Soos TJ, Xenias HS, Dubin-Thaler B, Hofman JM, Waite JC, et al. Opposing effects of PKCtheta and WASp on symmetry breaking and relocation of the immunological synapse. Cell (2007) 129(4):773-85. doi:10.1016/j. cell.2007.03.037

69. Skokos D, Shakhar G, Varma R, Waite JC, Cameron TO, Lindquist RL, et al. Peptide-MHC potency governs dynamic interactions between T cells and dendritic cells in lymph nodes. Nat Immunol (2007) 8(8):835-44. doi:10.1038/ni1490

70. Bhakta NR, Oh DY, Lewis RS. Calcium oscillations regulate thymocyte motility during positive selection in the three-dimensional thymic environment. Nat Immunol (2005) 6(2):143-51. doi:10.1038/ni1161

71. Wei SH, Safrina O, Yu Y, Garrod KR, Cahalan MD, Parker I. Ca2+ signals in $\mathrm{CD} 4+\mathrm{T}$ cells during early contacts with antigen-bearing dendritic cells in lymph node. J Immunol (2007) 179(3):1586-94. doi:10.4049/ jimmunol.179.3.1586

72. Campi G, Varma R, Dustin ML. Actin and agonist MHC-peptide complex-dependent $\mathrm{T}$ cell receptor microclusters as scaffolds for signaling. J Exp Med (2005) 202(8):1031-6. doi:10.1084/jem.20051182

73. Hashimoto-Tane A, Yokosuka T, Sakata-Sogawa K, Sakuma M, Ishihara C, Tokunaga $\mathrm{M}$, et al. Dynein-driven transport of $\mathrm{T}$ cell receptor microclusters regulates immune synapse formation and T cell activation. Immunity (2011) 34(6):919-31. doi:10.1016/j.immuni.2011.05.012

74. Smoligovets AA, Smith AW, Wu HJ, Petit RS, Groves JT. Characterization of dynamic actin associations with T-cell receptor microclusters in primary T cells. J Cell Sci (2012) 125(Pt 3):735-42. doi:10.1242/jcs.092825

75. Choudhuri K, Llodra J, Roth EW, Tsai J, Gordo S, Wucherpfennig KW, et al. Polarized release of T-cell-receptor-enriched microvesicles at the immunological synapse. Nature (2014) 507(7490):118-23. doi:10.1038/nature12951

76. Vardhana S, Choudhuri K, Varma R, Dustin ML. Essential role of ubiquitin and TSG101 protein in formation and function of the central supramolecular activation cluster. Immunity (2010) 32(4):531-40. doi:10.1016/j. immuni.2010.04.005

77. Mossman KD, Campi G, Groves JT, Dustin ML. Altered TCR signaling from geometrically repatterned immunological synapses. Science (2005) 310(5751):1191-3. doi:10.1126/science.1119238

78. Cemerski S, Das J, Giurisato E, Markiewicz MA, Allen PM, Chakraborty $\mathrm{AK}$, et al. The balance between $\mathrm{T}$ cell receptor signaling and degradation at the center of the immunological synapse is determined by antigen quality. Immunity (2008) 29(3):414-22. doi:10.1016/j.immuni.2008.06.014

79. Lim TS, Mortellaro A, Lim CT, Hammerling GJ, Ricciardi-Castagnoli P. Mechanical interactions between dendritic cells and $\mathrm{T}$ cells correlate with T cell responsiveness. J Immunol (2011) 187(1):258-65. doi:10.4049/ jimmunol.1100267

80. Judokusumo E, Tabdanov E, Kumari S, Dustin ML, Kam LC. Mechanosensing in T lymphocyte activation. Biophys J (2012) 102(2):L5-7. doi:10.1016/j. bpj.2011.12.011

81. O'Connor RS, Hao X, Shen K, Bashour K, Akimova T, Hancock WW, et al. Substrate rigidity regulates human $\mathrm{T}$ cell activation and proliferation. J Immunol (2012) 189(3):1330-9. doi:10.4049/jimmunol.1102757

82. Husson J, Chemin K, Bohineust A, Hivroz C, Henry N. Force generation upon T cell receptor engagement. PLoS One (2011) 6(5):e19680. doi:10.1371/ journal.pone.0019680

83. Wei X, Tromberg BJ, Cahalan MD. Mapping the sensitivity of T cells with an optical trap: polarity and minimal number of receptors for $\mathrm{Ca}(2+)$ signaling. Proc Natl Acad Sci U S A (1999) 96(15):8471-6. doi:10.1073/pnas.96.15.8471

84. Negulescu PA, Krasieva TB, Khan A, Kerschbaum HH, Cahalan MD. Polarity of T cell shape, motility, and sensitivity to antigen. Immunity (1996) 4(5):421-30. doi:10.1016/S1074-7613(00)80409-4

85. van der Merwe PA, Dushek O. Mechanisms for T cell receptor triggering. Nat Rev Immunol (2011) 11(1):47-55. doi:10.1038/nri2887

86. Huang J, Brameshuber M, Zeng X, Xie J, Li QJ, Chien YH, et al. A single peptide-major histocompatibility complex ligand triggers digital cytokine secretion in CD4(+) T cells. Immunity (2013) 39(5):846-57. doi:10.1016/j. immuni.2013.08.036

87. Nika K, Soldani C, Salek M, Paster W, Gray A, Etzensperger R, et al. Constitutively active Lck kinase in T cells drives antigen receptor signal transduction. Immunity (2010) 32(6):766-77. doi:10.1016/j.immuni.2010.05.011

88. Imbert V, Peyron JF, Farahi Far D, Mari B, Auberger P, Rossi B. Induction of tyrosine phosphorylation and T-cell activation by vanadate peroxide, an inhibitor of protein tyrosine phosphatases. Biochem J (1994) 297(Pt 1):163-73. doi:10.1042/bj2970163

89. Imbert V, Farahifar D, Auberger P, Mary D, Rossi B, Peyron JF. Stimulation of the T-cell antigen receptor-CD3 complex signaling pathway by the tyrosine phosphatase inhibitor pervanadate is mediated by inhibition of CD45: 
evidence for two interconnected Lck/Fyn- or zap-70-dependent signaling pathways. J Inflamm (1996) 46(2):65-77.

90. Secrist JP, Burns LA, Karnitz L, Koretzky GA, Abraham RT. Stimulatory effects of the protein tyrosine phosphatase inhibitor, pervanadate, on T-cell activation events. J Biol Chem (1993) 268(8):5886-93.

91. James JR, Vale RD. Biophysical mechanism of T-cell receptor triggering in a reconstituted system. Nature (2012) 487(7405):64-9. doi:10.1038/ nature 11220

92. Davis SJ, van der Merwe PA. The kinetic-segregation model: TCR triggering and beyond. Nat Immunol (2006) 7(8):803-9. doi:10.1038/ni1369

93. Hui E, Vale RD. In vitro membrane reconstitution of the T-cell receptor proximal signaling network. Nat Struct Mol Biol (2014) 21(2):133-42. doi: $10.1038 / \mathrm{nsmb} .2762$

94. Paszek MJ, DuFort CC, Rossier O, Bainer R, Mouw JK, Godula K, et al. The cancer glycocalyx mechanically primes integrin-mediated growth and survival. Nature (2014) 511(7509):319-25. doi:10.1038/nature13535

95. Cordoba SP, Choudhuri K, Zhang H, Bridge M, Basat AB, Dustin ML, et al. The large ectodomains of $\mathrm{CD} 45$ and $\mathrm{CD} 148$ regulate their segregation from and inhibition of ligated T-cell receptor. Blood (2013) 121(21):4295-302. doi:10.1182/blood-2012-07-442251

96. Irles C, Symons A, Michel F, Bakker TR, van der Merwe PA, Acuto O. CD45 ectodomain controls interaction with GEMs and Lck activity for optimal TCR signaling. Nat Immunol (2003) 4(2):189-97. doi:10.1038/ni877

97. Choudhuri K, Wiseman D, Brown MH, Gould K, van der Merwe PA. T-cell receptor triggering is critically dependent on the dimensions of its peptide-MHC ligand. Nature (2005) 436(7050):578-82. doi:10.1038/ nature 03843

98. Choudhuri K, Parker M, Milicic A, Cole DK, Shaw MK, Sewell AK, et al. Peptide-major histocompatibility complex dimensions control proximal kinase-phosphatase balance during T cell activation. J Biol Chem (2009) 284(38):26096-105. doi:10.1074/jbc.M109.039966

99. Douglass AD, Vale RD. Single-molecule microscopy reveals plasma membrane microdomains created by protein-protein networks that exclude or trap signaling molecules in T cells. Cell (2005) 121(6):937-50. doi:10.1016/j. cell.2005.04.009

100. Allenspach EJ, Cullinan P, Tong J, Tang Q, Tesciuba AG, Cannon JL, et al. ERM-dependent movement of CD43 defines a novel protein complex distal to the immunological synapse. Immunity (2001) 15(5):739-50. doi:10.1016/ S1074-7613(01)00224-2

101. Kohler K, Xiong S, Brzostek J, Mehrabi M, Eissmann P, Harrison A, et al. Matched sizes of activating and inhibitory receptor/ligand pairs are required for optimal signal integration by human natural killer cells. PLoS One (2010) 5(11):e15374. doi:10.1371/journal.pone.0015374

102. Almeida CR, Davis DM. Segregation of HLA-C from ICAM-1 at NK cell immune synapses is controlled by its cell surface density. J Immunol (2006) 177(10):6904-10. doi:10.4049/jimmunol.177.10.6904

103. Crites TJ, Padhan K, Muller J, Krogsgaard M, Gudla PR, Lockett SJ, et al. TCR microclusters pre-exist and contain molecules necessary for TCR signal transduction. J Immunol (2014) 193(1):56-67. doi:10.4049/ jimmunol.1400315

104. Bunnell SC, Hong DI, Kardon JR, Yamazaki T, McGlade CJ, Barr VA, et al. $\mathrm{T}$ cell receptor ligation induces the formation of dynamically regulated signaling assemblies. JCell Biol (2002) 158(7):1263-75. doi:10.1083/ jcb.200203043

105. McKeithan TW. Kinetic proofreading in T-cell receptor signal transduction. Proc Natl Acad Sci U S A (1995) 92(11):5042-6. doi:10.1073/pnas.92.11.5042

106. Dushek O, Das R, Coombs D. A role for rebinding in rapid and reliable T cell responses to antigen. PLoS Comput Biol (2009) 5(11):e1000578. doi:10.1371/ journal.pcbi.1000578

107. Govern CC, Paczosa MK, Chakraborty AK, Huseby ES. Fast on-rates allow short dwell time ligands to activate T cells. Proc Natl Acad Sci U S A (2010) 107(19):8724-9. doi:10.1073/pnas.1000966107

108. Aleksic M, Dushek O, Zhang H, Shenderov E, Chen JL, Cerundolo V, et al. Dependence of $\mathrm{T}$ cell antigen recognition on $\mathrm{T}$ cell receptor-peptide MHC confinement time. Immunity (2010) 32(2):163-74. doi:10.1016/j. immuni.2009.11.013

109. Huppa JB, Axmann M, Mortelmaier MA, Lillemeier BF, Newell EW, Brameshuber $\mathrm{M}$, et al. TCR-peptide-MHC interactions in situ show accelerated kinetics and increased affinity. Nature (2010) 463(7283):963-7. doi:10.1038/nature 08746

110. Huang J, Zarnitsyna VI, Liu B, Edwards LJ, Jiang N, Evavold BD, et al. The kinetics of two-dimensional TCR and pMHC interactions determine T-cell responsiveness. Nature (2010) 464(7290):932-6. doi:10.1038/nature08944

111. Liu B, Chen W, Evavold BD, Zhu C. Accumulation of dynamic catch bonds between TCR and agonist peptide-MHC triggers T cell signaling. Cell (2014) 157(2):357-68. doi:10.1016/j.cell.2014.02.053

112. Valitutti S, Muller S, Cella M, Padovan E, Lanzavecchia A. Serial triggering of many T-cell receptors by a few peptide-MHC complexes. Nature (1995) 375(6527):148-51. doi:10.1038/375148a0

113. Dustin ML, Depoil D. New insights into the $T$ cell synapse from single molecule techniques. Nat Rev Immunol (2011) 11(10):672-84. doi:10.1038/ nri3066

114. Gowrishankar K, Ghosh S, Saha S, C R, Mayor S, Rao M. Active remodeling of cortical actin regulates spatiotemporal organization of cell surface molecules. Cell (2012) 149(6):1353-67. doi:10.1016/j.cell.2012.05.008

115. Rozdzial MM, Malissen B, Finkel TH. Tyrosine-phosphorylated T cell receptor zeta chain associates with the actin cytoskeleton upon activation of mature $\mathrm{T}$ lymphocytes. Immunity (1995) 3(5):623-33. doi:10.1016/1074-7613(95)90133-7

116. Klieger Y, Almogi-Hazan O, Ish-Shalom E, Pato A, Pauker MH, Barda-Saad $\mathrm{M}$, et al. Unique zeta-chain motifs mediate a direct TCR-actin linkage critical for immunological synapse formation and T-cell activation. Eur J Immunol (2014) 44(1):58-68. doi:10.1002/eji.201243099

117. Rozdzial MM, Pleiman CM, Cambier JC, Finkel TH. pp56Lck mediates TCR zeta-chain binding to the microfilament cytoskeleton. JImmunol (1998) 161(10):5491-9.

118. Ma Z, Janmey PA, Finkel TH. The receptor deformation model of TCR triggering. FASEB J (2008) 22(4):1002-8. doi:10.1096/fj.07-9331hyp

119. Krogsgaard M, Prado N, Adams EJ, He XL, Chow DC, Wilson DB, et al. Evidence that structural rearrangements and/or flexibility during TCR binding can contribute to T cell activation. Mol Cell (2003) 12(6):1367-78. doi:10.1016/S1097-2765(03)00474-X

120. Beddoe T, Chen Z, Clements CS, Ely LK, Bushell SR, Vivian JP, et al. Antigen ligation triggers a conformational change within the constant domain of the alphabeta T cell receptor. Immunity (2009) 30(6):777-88. doi:10.1016/j. immuni.2009.03.018

121. Reiser JB, Gregoire C, Darnault C, Mosser T, Guimezanes A, Schmitt-Verhulst $\mathrm{AM}$, et al. A T cell receptor CDR3beta loop undergoes conformational changes of unprecedented magnitude upon binding to a peptide/MHC class I complex. Immunity (2002) 16(3):345-54. doi:10.1016/S1074-7613(02)00288-1

122. Lee JK, Stewart-Jones G, Dong T, Harlos K, Di Gleria K, Dorrell L, et al. T cell cross-reactivity and conformational changes during TCR engagement. J Exp Med (2004) 200(11):1455-66. doi:10.1084/jem.20041251

123. Fernandes RA, Shore DA, Vuong MT, Yu C, Zhu X, Pereira-Lopes S, et al. T cell receptors are structures capable of initiating signaling in the absence of large conformational rearrangements. J Biol Chem (2012) 287(16):13324-35. doi:10.1074/jbc.M111.332783

124. Cochran JR, Cameron TO, Stern LJ. The relationship of MHC-peptide binding and $\mathrm{T}$ cell activation probed using chemically defined MHC class II oligomers. Immunity (2000) 12(3):241-50. doi:10.1016/ S1074-7613(00)80177-6

125. Hamad AR, O’Herrin SM, Lebowitz MS, Srikrishnan A, Bieler J, Schneck $\mathrm{J}$, et al. Potent T cell activation with dimeric peptide-major histocompatibility complex class II ligand: the role of CD4 coreceptor. J Exp Med (1998) 188(9):1633-40. doi:10.1084/jem.188.9.1633

126. Appel H, Gauthier L, Pyrdol J, Wucherpfennig KW. Kinetics of T-cell receptor binding by bivalent HLA-DR. Peptide complexes that activate antigen-specific human T-cells. J Biol Chem (2000) 275(1):312-21. doi:10.1074/jbc.275.1.312

127. Boniface JJ, Rabinowitz JD, Wulfing C, Hampl J, Reich Z, Altman JD, et al. Initiation of signal transduction through the $\mathrm{T}$ cell receptor requires the multivalent engagement of peptide/MHC ligands [corrected]. Immunity (1998) 9(4):459-66. doi:10.1016/S1074-7613(00)80629-9

128. Casares S, Zong CS, Radu DL, Miller A, Bona CA, Brumeanu TD. Antigenspecific signaling by a soluble, dimeric peptide/major histocompatibility complex class II/Fc chimera leading to T helper cell type 2 differentiation. J Exp Med (1999) 190(4):543-53. doi:10.1084/jem.190.4.543 
129. Barda-Saad M, Braiman A, Titerence R, Bunnell SC, Barr VA, Samelson LE. Dynamic molecular interactions linking the $\mathrm{T}$ cell antigen receptor to the actin cytoskeleton. Nat Immunol (2005) 6(1):80-9. doi:10.1038/ni1143

130. Miletic AV, Graham DB, Sakata-Sogawa K, Hiroshima M, Hamann MJ, Cemerski S, et al. Vav links the T cell antigen receptor to the actin cytoskeleton and $\mathrm{T}$ cell activation independently of intrinsic guanine nucleotide exchange activity. PLoS One (2009) 4(8):e6599. doi:10.1371/journal.pone.0006599

131. Gil D, Schrum AG, Alarcon B, Palmer E. T cell receptor engagement by peptide-MHC ligands induces a conformational change in the $\mathrm{CD} 3$ complex of thymocytes. J Exp Med (2005) 201(4):517-22. doi:10.1084/ jem.20042036

132. Ma Z, Sharp KA, Janmey PA, Finkel TH. Surface-anchored monomeric agonist pMHCs alone trigger TCR with high sensitivity. PLoS Biol (2008) 6(2):e43. doi:10.1371/journal.pbio.0060043

133. Xie J, Huppa JB, Newell EW, Huang J, Ebert PJ, Li QJ, et al. Photocrosslinkable pMHC monomers stain T cells specifically and cause ligand-bound TCRs to be 'preferentially' transported to the cSMAC. Nat Immunol (2012) 13(7):674-80. doi:10.1038/ni.2344

134. Valitutti S, Dessing M, Aktories K, Gallati H, Lanzavecchia A. Sustained signaling leading to $\mathrm{T}$ cell activation results from prolonged $\mathrm{T}$ cell receptor occupancy. Role of T cell actin cytoskeleton. J Exp Med (1995) 181(2):577-84. doi:10.1084/jem.181.2.577

135. Rivas FV, O’Keefe JP, Alegre ML, Gajewski TF. Actin cytoskeleton regulates calcium dynamics and NFAT nuclear duration. Mol Cell Biol (2004) 24(4):1628-39. doi:10.1128/MCB.24.4.1628-1639.2004

136. Kim ST, Takeuchi K, Sun ZY, Touma M, Castro CE, Fahmy A, et al. The alphabeta $\mathrm{T}$ cell receptor is an anisotropic mechanosensor. JBiol Chem (2009) 284(45):31028-37. doi:10.1074/jbc.M109.052712

137. Kim ST, Shin Y, Brazin K, Mallis RJ, Sun ZY, Wagner G, et al. TCR mechanobiology: torques and tunable structures linked to early T cell signaling. Front Immunol (2012) 3:76. doi:10.3389/fimmu.2012.00076

138. Bashour KT, Gondarenko A, Chen H, Shen K, Liu X, Huse M, et al. CD28 and CD3 have complementary roles in T-cell traction forces. Proc Natl Acad Sci U S A (2014) 111(6):2241-6. doi:10.1073/pnas.1315606111

139. Hui KL, Balagopalan L, Samelson LE, Upadhyaya A. Cytoskeletal forces during signaling activation in Jurkat T-cells. Mol Biol Cell (2015) 26(4):68595. doi:10.1091/mbc.E14-03-0830

140. Pryshchep S, Zarnitsyna VI, Hong J, Evavold BD, Zhu C. Accumulation of serial forces on TCR and CD8 frequently applied by agonist antigenic peptides embedded in MHC molecules triggers calcium in T cells. J Immunol (2014) 193(1):68-76. doi:10.4049/jimmunol.1303436

141. Zhang H, Cordoba SP, Dushek O, van der Merwe PA. Basic residues in the T-cell receptor zeta cytoplasmic domain mediate membrane association and modulate signaling. Proc Natl Acad Sci U S A (2011) 108(48):19323-8. doi:10.1073/pnas.1108052108

142. Aivazian D, Stern LJ. Phosphorylation of T cell receptor zeta is regulated by a lipid dependent folding transition. Nat Struct Biol (2000) 7(11):1023-6. doi: $10.1038 / 80930$

143. DeFord-Watts LM, Dougall DS, Belkaya S, Johnson BA, Eitson JL, Roybal $\mathrm{KT}$, et al. The $\mathrm{CD} 3$ zeta subunit contains a phosphoinositide-binding motif that is required for the stable accumulation of TCR-CD3 complex at the immunological synapse. J Immunol (2011) 186(12):6839-47. doi:10.4049/ jimmunol.1002721

144. Xu C, Gagnon E, Call ME, Schnell JR, Schwieters CD, Carman CV, et al. Regulation of $\mathrm{T}$ cell receptor activation by dynamic membrane binding of the CD3epsilon cytoplasmic tyrosine-based motif. Cell (2008) 135(4):702-13. doi:10.1016/j.cell.2008.09.044

145. Gil D, Schamel WW, Montoya M, Sanchez-Madrid F, Alarcon B. Recruitment of Nck by $\mathrm{CD} 3$ epsilon reveals a ligand-induced conformational change essential for T cell receptor signaling and synapse formation. Cell (2002) 109(7):901-12. doi:10.1016/\$0092-8674(02)00799-7

146. Borroto A, Arellano I, Blanco R, Fuentes M, Orfao A, Dopfer EP, et al. Relevance of Nck-CD3 epsilon interaction for $\mathrm{T}$ cell activation in vivo. J Immunol (2014) 192(5):2042-53. doi:10.4049/jimmunol.1203414

147. Borroto A, Arellano I, Dopfer EP, Prouza M, Suchanek M, Fuentes M, et al. Nck recruitment to the TCR required for ZAP70 activation during thymic development. J Immunol (2013) 190(3):1103-12. doi:10.4049/ jimmunol.1202055
148. Donnelly SK, Weisswange I, Zettl M, Way M. WIP provides an essential link between Nck and N-WASP during Arp2/3-dependent actin polymerization. Curr Biol (2013) 23(11):999-1006. doi:10.1016/j.cub.2013.04.051

149. Zeng R, Cannon JL, Abraham RT, Way M, Billadeau DD, Bubeck-Wardenberg J, et al. SLP-76 coordinates Nck-dependent Wiskott-Aldrich syndrome protein recruitment with Vav-1/Cdc42-dependent Wiskott-Aldrich syndrome protein activation at the T cell-APC contact site. J Immunol (2003) 171(3):1360-8. doi:10.4049/jimmunol.171.3.1360

150. Zhang X, Moore SW, Iskratsch T, Sheetz MP. N-WASP-directed actin polymerization activates Cas phosphorylation and lamellipodium spreading. J Cell Sci (2014) 127(Pt 7):1394-405. doi:10.1242/jcs.134692

151. Thomas WE, Vogel V, Sokurenko E. Biophysics of catch bonds. Annu Rev Biophys (2008) 37:399-416. doi:10.1146/annurev.biophys.37.032807.125804

152. Hosseini BH, Louban I, Djandji D, Wabnitz GH, Deeg J, Bulbuc N, et al. Immune synapse formation determines interaction forces between $\mathrm{T}$ cells and antigen-presenting cells measured by atomic force microscopy. Proc Natl Acad Sci U S A (2009) 106(42):17852-7. doi:10.1073/ pnas.0905384106

153. Hoffmann S, Hosseini BH, Hecker M, Louban I, Bulbuc N, Garbi N, et al. Single cell force spectroscopy of $\mathrm{T}$ cells recognizing a myelin-derived peptide on antigen presenting cells. Immunol Lett (2011) 136(1):13-20. doi:10.1016/j. imlet.2010.11.005

154. Yu T, Wu X, Gupta KB, Kucik DF. Affinity, lateral mobility, and clustering contribute independently to beta 2-integrin-mediated adhesion. Am J Physiol Cell Physiol (2010) 299(2):C399-410. doi:10.1152/ajpcell.00039.2009

155. Kinashi T. Intracellular signalling controlling integrin activation in lymphocytes. Nat Rev Immunol (2005) 5(7):546-59. doi:10.1038/nri1646

156. Hogg N, Patzak I, Willenbrock F. The insider's guide to leukocyte integrin signalling and function. Nat Rev Immunol (2011) 11(6):416-26. doi:10.1038/ nri2986

157. Kim C, Ye F, Ginsberg MH. Regulation of integrin activation. Annu Rev Cell Dev Biol (2011) 27:321-45. doi:10.1146/annurev-cellbio-100109-104104

158. Luo BH, Carman CV, Springer TA. Structural basis of integrin regulation and signaling. Annu Rev Immunol (2007) 25:619-47. doi:10.1146/annurev. immunol.25.022106.141618

159. Springer TA, Dustin ML. Integrin inside-out signaling and the immunological synapse. Curr Opin Cell Biol (2012) 24(1):107-15. doi:10.1016/j. ceb.2011.10.004

160. Ciobanasu C, Faivre B, Le Clainche C. Integrating actin dynamics, mechanotransduction and integrin activation: the multiple functions of actin binding proteins in focal adhesions. Eur J Cell Biol (2013) 92(10-11):339-48. doi:10.1016/j.ejcb.2013.10.009

161. Katagiri K, Shimonaka M, Kinashi T. Rap1-mediated lymphocyte function-associated antigen- 1 activation by the $\mathrm{T}$ cell antigen receptor is dependent on phospholipase C-gamma1. J Biol Chem (2004) 279(12):11875-81. doi:10.1074/jbc.M310717200

162. Letschka T, Kollmann V, Pfeifhofer-Obermair C, Lutz-Nicoladoni C, Obermair GJ, Fresser F, et al. PKC-theta selectively controls the adhesion-stimulating molecule Rap1. Blood (2008) 112(12):4617-27. doi:10.1182/ blood-2007-11-121111

163. Ghandour H, Cullere X, Alvarez A, Luscinskas FW, Mayadas TN. Essential role for Rap1 GTPase and its guanine exchange factor CalDAG-GEFI in LFA- 1 but not VLA- 4 integrin mediated human T-cell adhesion. Blood (2007) 110(10):3682-90. doi:10.1182/blood-2007-03-077628

164. Nolz JC, Nacusi LP, Segovis CM, Medeiros RB, Mitchell JS, Shimizu Y, et al. The WAVE2 complex regulates $\mathrm{T}$ cell receptor signaling to integrins via Abl- and CrkL-C3G-mediated activation of Rap1. J Cell Biol (2008) 182(6):1231-44. doi:10.1083/jcb.200801121

165. Lee HS, Lim CJ, Puzon-McLaughlin W, Shattil SJ, Ginsberg MH. RIAM activates integrins by linking talin to ras GTPase membrane-targeting sequences. J Biol Chem (2009) 284(8):5119-27. doi:10.1074/jbc.M807117200

166. Simonson WT, Franco SJ, Huttenlocher A. Talin1 regulates TCR-mediated LFA-1 function. JImmunol (2006) 177(11):7707-14. doi:10.4049/ jimmunol.177.11.7707

167. Calderwood DA, Zent R, Grant R, Rees DJ, Hynes RO, Ginsberg MH. The talin head domain binds to integrin beta subunit cytoplasmic tails and regulates integrin activation. J Biol Chem (1999) 274(40):28071-4. doi:10.1074/ jbc.274.40.28071 
168. Hughes PE, Diaz-Gonzalez F, Leong L, Wu C, McDonald JA, Shattil SJ, et al. Breaking the integrin hinge. A defined structural constraint regulates integrin signaling. J Biol Chem (1996) 271(12):6571-4.

169. Kim M, Carman CV, Springer TA. Bidirectional transmembrane signaling by cytoplasmic domain separation in integrins. Science (2003) 301(5640):17205. doi:10.1126/science.1084174

170. Li R, Mitra N, Gratkowski H, Vilaire G, Litvinov R, Nagasami C, et al. Activation of integrin alphaIIbbeta 3 by modulation of transmembrane helix associations. Science (2003) 300(5620):795-8. doi:10.1126/science.1079441

171. Luo BH, Carman CV, Takagi J, Springer TA. Disrupting integrin transmembrane domain heterodimerization increases ligand binding affinity, not valency or clustering. Proc Natl Acad Sci U S A (2005) 102(10):3679-84. doi:10.1073/pnas.0409440102

172. Partridge AW, Liu S, Kim S, Bowie JU, Ginsberg MH. Transmembrane domain helix packing stabilizes integrin alphaIIbbeta 3 in the low affinity state. J Biol Chem (2005) 280(8):7294-300. doi:10.1074/jbc.M412701200

173. Tadokoro S, Shattil SJ, Eto K, Tai V, Liddington RC, de Pereda JM, et al. Talin binding to integrin beta tails: a final common step in integrin activation. Science (2003) 302(5642):103-6. doi:10.1126/science.1086652

174. Kim C, Ye F, Hu X, Ginsberg MH. Talin activates integrins by altering the topology of the beta transmembrane domain. J Cell Biol (2012) 197(5):60511. doi: $10.1083 / \mathrm{jcb} .201112141$

175. Schurpf T, Springer TA. Regulation of integrin affinity on cell surfaces. $E M B O$ $J(2011)$ 30(23):4712-27. doi:10.1038/emboj.2011.333

176. Takagi J, Petre BM, Walz T, Springer TA. Global conformational rearrangements in integrin extracellular domains in outside-in and inside-out signaling. Cell (2002) 110(5):599-611. doi:10.1016/S0092-8674(02)00935-2

177. Nishida N, Xie C, Shimaoka M, Cheng Y, Walz T, Springer TA. Activation of leukocyte beta2 integrins by conversion from bent to extended conformations. Immunity (2006) 25(4):583-94. doi:10.1016/j.immuni.2006.07.016

178. Li YF, Tang RH, Puan KJ, Law SK, Tan SM. The cytosolic protein talin induces an intermediate affinity integrin alphaLbeta2. J Biol Chem (2007) 282(33):24310-9. doi:10.1074/jbc.M701860200

179. Feigelson SW, Grabovsky V, Manevich-Mendelson E, Pasvolsky R, Shulman Z, Shinder V, et al. Kindlin-3 is required for the stabilization of TCR-stimulated LFA-1:ICAM-1 bonds critical for lymphocyte arrest and spreading on dendritic cells. Blood (2011) 117(26):7042-52. doi:10.1182/ blood-2010-12-322859

180. Kucik DF, Dustin ML, Miller JM, Brown EJ. Adhesion-activating phorbol ester increases the mobility of leukocyte integrin LFA-1 in cultured lymphocytes. J Clin Invest (1996) 97(9):2139-44. doi:10.1172/JCI118651

181. Bleijs DA, van Duijnhoven GC, van Vliet SJ, Thijssen JP, Figdor CG, van Kooyk Y. A single amino acid in the cytoplasmic domain of the beta 2 integrin lymphocyte function-associated antigen-1 regulates avidity-dependent inside-out signaling. J Biol Chem (2001) 276(13):10338-46. doi:10.1074/jbc. M008967200

182. Stewart MP, McDowall A, Hogg N. LFA-1-mediated adhesion is regulated by cytoskeletal restraint and by a Ca2+-dependent protease, calpain. J Cell Biol (1998) 140(3):699-707. doi:10.1083/jcb.140.3.699

183. Bakker GJ, Eich C, Torreno-Pina JA, Diez-Ahedo R, Perez-Samper G, van Zanten TS, et al. Lateral mobility of individual integrin nanoclusters orchestrates the onset for leukocyte adhesion. Proc Natl Acad Sci U S A (2012) 109(13):4869-74. doi:10.1073/pnas.1116425109

184. Kim M, Carman CV, Yang W, Salas A, Springer TA. The primacy of affinity over clustering in regulation of adhesiveness of the integrin $\{$ alpha $\} \mathrm{L}\{$ beta $\} 2$. J Cell Biol (2004) 167(6):1241-53. doi:10.1083/jcb.200404160

185. Kaizuka Y, Douglass AD, Varma R, Dustin ML, Vale RD. Mechanisms for segregating $\mathrm{T}$ cell receptor and adhesion molecules during immunological synapse formation in Jurkat T cells. Proc Natl Acad Sci U S A (2007) 104(51):20296-301. doi:10.1073/pnas.0710258105

186. Shimaoka M, Xiao T, Liu JH, Yang Y, Dong Y, Jun CD, et al. Structures of the alpha L I domain and its complex with ICAM-1 reveal a shape-shifting pathway for integrin regulation. Cell (2003) 112(1):99-111. doi:10.1016/ S0092-8674(02)01257-6

187. Weitz-Schmidt G, Schurpf T, Springer TA. The C-terminal alphaI domain linker as a critical structural element in the conformational activation of alphaI integrins. J Biol Chem (2011) 286(49):42115-22. doi:10.1074/jbc. M111.282830
188. Zhu J, Luo BH, Xiao T, Zhang C, Nishida N, Springer TA. Structure of a complete integrin ectodomain in a physiologic resting state and activation and deactivation by applied forces. Mol Cell (2008) 32(6):849-61. doi:10.1016/j. molcel.2008.11.018

189. Zhu J, Zhu J, Springer TA. Complete integrin headpiece opening in eight steps. J Cell Biol (2013) 201(7):1053-68. doi:10.1083/jcb.201212037

190. Chen X, Xie C, Nishida N, Li Z, Walz T, Springer TA. Requirement of open headpiece conformation for activation of leukocyte integrin alphaXbeta2.Proc Natl Acad Sci U S A (2010) 107(33):14727-32. doi:10.1073/pnas.1008663107

191. Chen W, Lou J, Hsin J, Schulten K, Harvey SC, Zhu C. Molecular dynamics simulations of forced unbending of integrin alpha(v)beta(3). PLoS Comput Biol (2011) 7(2):e1001086. doi:10.1371/journal.pcbi.1001086

192. Cairo CW, Mirchev R, Golan DE. Cytoskeletal regulation couples LFA-1 conformational changes to receptor lateral mobility and clustering. Immunity (2006) 25(2):297-308. doi:10.1016/j.immuni.2006.06.012

193. Comrie WA, Babich A, Burkhardt JK. F-actin flow drives affinity maturation and spatial organization of LFA-1 at the immunological synapse. J Cell Biol (2015) 208(4):475-91. doi:10.1083/jcb.201406121

194. Kong F, Garcia AJ, Mould AP, Humphries MJ, Zhu C. Demonstration of catch bonds between an integrin and its ligand. J Cell Biol (2009) 185(7):1275-84. doi:10.1083/jcb.200810002

195. Chen W, Lou J, Evans EA, Zhu C. Observing force-regulated conformational changes and ligand dissociation from a single integrin on cells. J Cell Biol (2012) 199(3):497-512. doi:10.1083/jcb.201201091

196. Chen W, Lou J, Zhu C. Forcing switch from short- to intermediate- and longlived states of the alphaA domain generates LFA-1/ICAM-1 catch bonds. J Biol Chem (2010) 285(46):35967-78. doi:10.1074/jbc.M110.155770

197. Thomas W. Catch bonds in adhesion. Annu Rev Biomed Eng (2008) 10:39-57. doi:10.1146/annurev.bioeng.10.061807.160427

198. Kong F, Li Z, Parks WM, Dumbauld DW, Garcia AJ, Mould AP, et al. Cyclic mechanical reinforcement of integrin-ligand interactions. Mol Cell (2013) 49(6):1060-8. doi:10.1016/j.molcel.2013.01.015

199. Roca-Cusachs P, Iskratsch T, Sheetz MP. Finding the weakest link: exploring integrin-mediated mechanical molecular pathways. J Cell Sci (2012) 125(Pt 13):3025-38. doi:10.1242/jcs.095794

200. del Rio A, Perez-Jimenez R, Liu R, Roca-Cusachs P, Fernandez JM, Sheetz MP. Stretching single talin rod molecules activates vinculin binding. Science (2009) 323(5914):638-41. doi:10.1126/science.1162912

201. Hirata H, Tatsumi H, Lim CT, Sokabe M. Force-dependent vinculin binding to talin in live cells: a crucial step in anchoring the actin cytoskeleton to focal adhesions. Am J Physiol Cell Physiol (2014) 306(6):C607-20. doi:10.1152/ ajpcell.00122.2013

202. Menkel AR, Kroemker M, Bubeck P, Ronsiek M, Nikolai G, Jockusch BM. Characterization of an F-actin-binding domain in the cytoskeletal protein vinculin. J Cell Biol (1994) 126(5):1231-40. doi:10.1083/jcb.126.5.1231

203. MargadantF,ChewLL, HuX, YuH,BateN,ZhangX, etal.Mechanotransduction in vivo by repeated talin stretch-relaxation events depends upon vinculin. PLoS Biol (2011) 9(12):e1001223. doi:10.1371/journal.pbio.1001223

204. Ciobanasu C, Faivre B, Le Clainche C. Actomyosin-dependent formation of the mechanosensitive talin-vinculin complex reinforces actin anchoring. Nat Commun (2014) 5:3095. doi:10.1038/ncomms4095

205. Schiller HB, Fassler R. Mechanosensitivity and compositional dynamics of cell-matrix adhesions. EMBO Rep (2013) 14(6):509-19. doi:10.1038/ embor.2013.49

206. Nolz JC, Medeiros RB, Mitchell JS, Zhu P, Freedman BD, Shimizu Y, et al. WAVE2 regulates high-affinity integrin binding by recruiting vinculin and talin to the immunological synapse. Mol Cell Biol (2007) 27(17):5986-6000. doi:10.1128/MCB.00136-07

207. Wang Y, Li D, Nurieva R, Yang J, Sen M, Carreno R, et al. LFA-1 affinity regulation is necessary for the activation and proliferation of naive $\mathrm{T}$ cells. J Biol Chem (2009) 284(19):12645-53. doi:10.1074/jbc.M807207200

208. Zhu J, Carman CV, Kim M, Shimaoka M, Springer TA, Luo BH. Requirement of alpha and beta subunit transmembrane helix separation for integrin outside-in signaling. Blood (2007) 110(7):2475-83. doi:10.1182/ blood-2007-03-080077

209. Henning SW, Meuer SC, Samstag Y. Serine phosphorylation of a $67-\mathrm{kDa}$ protein in human $\mathrm{T}$ lymphocytes represents an accessory receptor-mediated signaling event. J Immunol (1994) 152(10):4808-15. 
210. Singleton K, Parvaze N, Dama KR, Chen KS, Jennings P, Purtic B, et al. A large $\mathrm{T}$ cell invagination with $\mathrm{CD} 2$ enrichment resets receptor engagement in the immunological synapse. JImmunol (2006) 177(7):4402-13. doi:10.4049/ jimmunol.177.7.4402

211. Wabnitz GH, Kocher T, Lohneis P, Stober C, Konstandin MH, Funk B, et al. Costimulation induced phosphorylation of L-plastin facilitates surface transport of the $\mathrm{T}$ cell activation molecules $\mathrm{CD} 69$ and CD25. Eur J Immunol (2007) 37(3):649-62. doi:10.1002/eji.200636320

212. Yokosuka T, Kobayashi W, Sakata-Sogawa K, Takamatsu M, Hashimoto-Tane A, Dustin ML, et al. Spatiotemporal regulation of $\mathrm{T}$ cell costimulation by TCR-CD28 microclusters and protein kinase $\mathrm{C}$ theta translocation. Immunity (2008) 29(4):589-601. doi:10.1016/j.immuni.2008.08.011

213. Lim TS, Goh JK, Mortellaro A, Lim CT, Hammerling GJ, Ricciardi-Castagnoli P. CD80 and CD86 differentially regulate mechanical interactions of T-cells with antigen-presenting dendritic cells and B-cells. PLoS One (2012) 7(9):e45185. doi:10.1371/journal.pone.0045185

214. Tavano R, Contento RL, Baranda SJ, Soligo M, Tuosto L, Manes S, et al. CD28 interaction with filamin-A controls lipid raft accumulation at the T-cell immunological synapse. Nat Cell Biol (2006) 8(11):1270-6. doi:10.1038/ ncb1492

215. Kim H, McCulloch CA. Filamin A mediates interactions between cytoskeletal proteins that control cell adhesion. FEBS Lett (2011) 585(1):18-22. doi:10.1016/j.febslet.2010.11.033

216. Razinia Z, Makela T, Ylanne J, Calderwood DA. Filamins in mechanosensing and signaling. Annu Rev Biophys (2012) 41:227-46. doi:10.1146/ annurev-biophys-050511-102252

217. Ehrlicher AJ, Nakamura F, Hartwig JH, Weitz DA, Stossel TP. Mechanical strain in actin networks regulates FilGAP and integrin binding to filamin A. Nature (2011) 478(7368):260-3. doi:10.1038/nature10430

218. Lynch CD, Sheetz MP. Cellular mechanotransduction: filamin A strains to regulate motility. Curr Biol (2011) 21(22):R916-8. doi:10.1016/j. cub.2011.10.020

219. Sawada Y, Tamada M, Dubin-Thaler BJ, Cherniavskaya O, Sakai R, Tanaka S, et al. Force sensing by mechanical extension of the Src family kinase substrate p130Cas. Cell (2006) 127(5):1015-26. doi:10.1016/j.cell.2006.09.044

220. Tamada M, Sheetz MP, Sawada Y. Activation of a signaling cascade by cytoskeleton stretch. Dev Cell (2004) 7(5):709-18. doi:10.1016/j.devcel.2004.08.021

221. Yu Y, Fay NC, Smoligovets AA, Wu HJ, Groves JT. Myosin IIA modulates $\mathrm{T}$ cell receptor transport and CasL phosphorylation during early immunological synapse formation. PLoS One (2012) 7(2):e30704. doi:10.1371/ journal.pone.0030704

222. Kumari S, Vardhana S, Cammer M, Curado S, Santos L, Sheetz MP, et al. $\mathrm{T}$ lymphocyte myosin IIA is required for maturation of the immunological synapse. Front Immunol (2012) 3:230. doi:10.3389/fimmu.2012.00230

223. Wang X, Ha T. Defining single molecular forces required to activate integrin and notch signaling. Science (2013) 340(6135):991-4. doi:10.1126/ science. 1231041

224. Chen H, ChandrasekarS, Sheetz MP, Stossel TP, Nakamura F, Yan J. Mechanical perturbation of filamin A immunoglobulin repeats 20-21 reveals potential non-equilibrium mechanochemical partner binding function. Sci Rep (2013) 3:1642. doi:10.1038/srep01642

225. Yao M, Goult BT, Chen H, Cong P, Sheetz MP, Yan J. Mechanical activation of vinculin binding to talin locks talin in an unfolded conformation. Sci Rep (2014) 4:4610. doi:10.1038/srep04610

226. Dustin ML, Tseng SY, Varma R, Campi G. T cell-dendritic cell immunological synapses. Curr Opin Immunol (2006) 18(4):512-6. doi:10.1016/j. coi.2006.05.017

227. Grakoui A, Bromley SK, Sumen C, Davis MM, Shaw AS, Allen PM, et al. The immunological synapse: a molecular machine controlling $\mathrm{T}$ cell activation. Science (1999) 285(5425):221-7. doi:10.1126/science.285.5425.221

228. Monks CR, Freiberg BA, Kupfer H, Sciaky N, Kupfer A. Three-dimensional segregation of supramolecular activation clusters in T cells. Nature (1998) 395(6697):82-6. doi:10.1038/25764

229. Brossard C, Feuillet V, Schmitt A, Randriamampita C, Romao M, Raposo G, et al. Multifocal structure of the T cell - dendritic cell synapse. Eur J Immunol (2005) 35(6):1741-53. doi:10.1002/eji.200425857

230. Al-Alwan MM, Liwski RS, Haeryfar SM, Baldridge WH, Hoskin DW, Rowden $\mathrm{G}$, et al. Cutting edge: dendritic cell actin cytoskeletal polarization during immunological synapse formation is highly antigen-dependent. J Immunol (2003) 171(9):4479-83. doi:10.4049/jimmunol.171.9.4479

231. Al-Alwan MM, Rowden G, Lee TD, West KA. The dendritic cell cytoskeleton is critical for the formation of the immunological synapse. J Immunol (2001) 166(3):1452-6. doi:10.4049/jimmunol.166.3.1452

232. Benvenuti F, Hugues S, Walmsley M, Ruf S, Fetler L, Popoff M, et al. Requirement of Rac1 and Rac2 expression by mature dendritic cells for $\mathrm{T}$ cell priming. Science (2004) 305(5687):1150-3. doi:10.1126/science.1099159

233. Rothoeft T, Balkow S, Krummen M, Beissert S, Varga G, Loser K, et al. Structure and duration of contact between dendritic cells and $\mathrm{T}$ cells are controlled by T cell activation state. Eur J Immunol (2006) 36(12):3105-17. doi:10.1002/eji.200636145

234. Eun SY, O’Connor BP, Wong AW, van Deventer HW, Taxman DJ, Reed W, et al. Cutting edge: rho activation and actin polarization are dependent on plexin-A1 in dendritic cells. J Immunol (2006) 177(7):4271-5. doi:10.4049/ jimmunol.177.7.4271

235. Bouma G, Mendoza-Naranjo A, Blundell MP, de Falco E, Parsley KL, Burns SO, et al. Cytoskeletal remodeling mediated by WASp in dendritic cells is necessary for normal immune synapse formation and T-cell priming. Blood (2011) 118(9):2492-501. doi:10.1182/blood-2011-03-340265

236. Pulecio J, Tagliani E, Scholer A, Prete F, Fetler L, Burrone OR, et al. Expression of Wiskott-Aldrich syndrome protein in dendritic cells regulates synapse formation and activation of naive CD8+ T cells. J Immunol (2008) 181(2):1135-42. doi:10.4049/jimmunol.181.2.1135

237. Ross R, Jonuleit H, Bros M, Ross XL, Yamashiro S, Matsumura F, et al. Expression of the actin-bundling protein fascin in cultured human dendritic cells correlates with dendritic morphology and cell differentiation. J Invest Dermatol (2000) 115(4):658-63. doi:10.1046/j.1523-1747.2000.00112.x

238. Bros M, Ross XL, Pautz A, Reske-Kunz AB, Ross R. The human fascin gene promoter is highly active in mature dendritic cells due to a stage-specific enhancer. J Immunol (2003) 171(4):1825-34. doi:10.4049/ jimmunol.171.4.1825

239. Verdijk P, van Veelen PA, de Ru AH, Hensbergen PJ, Mizuno K, Koerten $\mathrm{HK}$, et al. Morphological changes during dendritic cell maturation correlate with cofilin activation and translocation to the cell membrane. Eur J Immunol (2004) 34(1):156-64. doi:10.1002/eji.200324241

240. Comrie WA, Li S, Boyle S, Burkhardt JK. The dendritic cell cytoskeleton promotes $\mathrm{T}$ cell adhesion and activation by constraining ICAM-1 mobility. J Cell Biol (2015) 208(4):457-73. doi:10.1083/jcb.201406120

241. Breitsprecher D, Koestler SA, Chizhov I, Nemethova M, Mueller J, Goode BL, et al. Cofilin cooperates with fascin to disassemble filopodial actin filaments. J Cell Sci (2011) 124(Pt 19):3305-18. doi:10.1242/jcs.086934

242. Garrett WS, Chen LM, Kroschewski R, Ebersold M, Turley S, Trombetta S, et al. Developmental control of endocytosis in dendritic cells by Cdc42. Cell (2000) 102(3):325-34. doi:10.1016/S0092-8674(00)00038-6

243. Wong AW, Brickey WJ, Taxman DJ, van Deventer HW, Reed W, Gao JX, et al. CIITA-regulated plexin-A1 affects T-cell-dendritic cell interactions. Nat Immunol (2003) 4(9):891-8. doi:10.1038/ni960

244. Hsu CJ, Hsieh WT, Waldman A, Clarke F, Huseby ES, Burkhardt JK, et al. Ligand mobility modulates immunological synapse formation and $\mathrm{T}$ cell activation. PLoS One (2012) 7(2):e32398. doi:10.1371/journal.pone.0032398

245. Yu CH, Wu HJ, Kaizuka Y, Vale RD, Groves JT. Altered actin centripetal retrograde flow in physically restricted immunological synapses. PLoS One (2010) 5(7):e11878. doi:10.1371/journal.pone.0011878

246. Edidin M, Stroynowski I. Differences between the lateral organization of conventional and inositol phospholipid-anchored membrane proteins. A further definition of micrometer scale membrane domains. JCell Biol (1991) 112(6):1143-50. doi:10.1083/jcb.112.6.1143

247. Kwik J, Boyle S, Fooksman D, Margolis L, Sheetz MP, Edidin M. Membrane cholesterol, lateral mobility, and the phosphatidylinositol 4,5-bisphosphate-dependent organization of cell actin. Proc Natl Acad Sci U S A (2003) 100(24):13964-9. doi:10.1073/pnas.2336102100

248. Lavi Y, Gov N, Edidin M, Gheber LA. Lifetime of major histocompatibility complex class-I membrane clusters is controlled by the actin cytoskeleton. Biophys J (2012) 102(7):1543-50. doi:10.1016/j.bpj.2012.01.042

249. Friedland JC, Lee MH, Boettiger D. Mechanically activated integrin switch controls alpha5betal function. Science (2009) 323(5914):642-4. doi:10.1126/ science. 1168441 
250. Feigelson SW, Pasvolsky R, Cemerski S, Shulman Z, Grabovsky V, Ilani T, et al. Occupancy of lymphocyte LFA-1 by surface-immobilized ICAM-1 is critical for TCR- but not for chemokine-triggered LFA-1 conversion to an open headpiece high-affinity state. J Immunol (2010) 185(12):7394-404. doi:10.4049/jimmunol.1002246

251. Gross CC, Brzostowski JA, Liu D, Long EO. Tethering of intercellular adhesion molecule on target cells is required for LFA-1-dependent NK cell adhesion and granule polarization. J Immunol (2010) 185(5):2918-26. doi:10.4049/jimmunol.1000761

252. Celli L, Ryckewaert JJ, Delachanal E, Duperray A. Evidence of a functional role for interaction between ICAM-1 and nonmuscle alpha-actinins in leukocyte diapedesis. J Immunol (2006) 177(6):4113-21. doi:10.4049/ jimmunol.177.6.4113

253. Oh HM, Lee S, Na BR, Wee H, Kim SH, Choi SC, et al. RKIKK motif in the intracellular domain is critical for spatial and dynamic organization of ICAM-1: functional implication for the leukocyte adhesion and transmigration. Mol Biol Cell (2007) 18(6):2322-35. doi:10.1091/mbc.E06-08-0744

254. Tseng SY, Liu M, Dustin ML. CD80 cytoplasmic domain controls localization of CD28, CTLA-4, and protein kinase Ctheta in the immunological synapse. J Immunol (2005) 175(12):7829-36. doi:10.4049/jimmunol.175.12.7829

255. Doty RT, Clark EA. Two regions in the CD80 cytoplasmic tail regulate CD80 redistribution and T cell costimulation. J Immunol (1998) 161(6):2700-7.

256. Girard T, El-Far M, Gaucher D, Acuto O, Beaule G, Michel F, et al. A conserved polylysine motif in CD86 cytoplasmic tail is necessary for cytoskeletal association and effective co-stimulation. Biochem Biophys Res Commun (2012) 423(2):301-7. doi:10.1016/j.bbrc.2012.05.116

257. Yonemura S, Hirao M, Doi Y, Takahashi N, Kondo T, Tsukita S, et al. Ezrin/ radixin/moesin (ERM) proteins bind to a positively charged amino acid cluster in the juxta-membrane cytoplasmic domain of CD44, CD43, and ICAM-2. J Cell Biol (1998) 140(4):885-95. doi:10.1083/jcb.140.4.885

258. Barreiro O, Yanez-Mo M, Serrador JM, Montoya MC, Vicente-Manzanares M, Tejedor R, et al. Dynamic interaction of VCAM-1 and ICAM-1 with moesin and ezrin in a novel endothelial docking structure for adherent leukocytes. J Cell Biol (2002) 157(7):1233-45. doi:10.1083/jcb.200112126

259. Koss M, Pfeiffer GR II, Wang Y, Thomas ST, Yerukhimovich M, Gaarde WA, et al. Ezrin/radixin/moesin proteins are phosphorylated by TNF-alpha and modulate permeability increases in human pulmonary microvascular endothelial cells. J Immunol (2006) 176(2):1218-27. doi:10.4049/ jimmunol.176.2.1218
260. Li YC, Chen BM, Wu PC, Cheng TL, Kao LS, Tao MH, et al. Cutting edge: mechanical forces acting on T cells immobilized via the TCR complex can trigger TCR signaling. J Immunol (2010) 184(11):5959-63. doi:10.4049/ jimmunol.0900775

261. Grashoff C, Hoffman BD, Brenner MD, Zhou R, Parsons M, Yang MT, et al. Measuring mechanical tension across vinculin reveals regulation of focal adhesion dynamics. Nature (2010) 466(7303):263-6. doi:10.1038/ nature09198

262. Jurchenko C, Salaita KS. Lighting up the force: investigating mechanisms of mechanotransduction using fluorescent tension probes. Mol Cell Biol (2015) 35(15):2570-82. doi:10.1128/MCB.00195-15

263. Lefort CT, Hyun YM, Kim M. Monitoring integrin activation by fluorescence resonance energy transfer. Methods Mol Biol (2012) 757:205-14. doi:10.1007/978-1-61779-166-6_14

264. Morimatsu M, Mekhdjian AH, Adhikari AS, Dunn AR. Molecular tension sensors report forces generated by single integrin molecules in living cells. Nano Lett (2013) 13(9):3985-9. doi:10.1021/nl4005145

265. Stabley DR, Jurchenko C, Marshall SS, Salaita KS. Visualizing mechanical tension across membrane receptors with a fluorescent sensor. Nat Methods (2012) 9(1):64-7. doi:10.1038/nmeth.1747

266. Kalos M, June $\mathrm{CH}$. Adoptive $\mathrm{T}$ cell transfer for cancer immunotherapy in the era of synthetic biology. Immunity (2013) 39(1):49-60. doi:10.1016/j. immuni.2013.07.002

267. Restifo NP, Dudley ME, Rosenberg SA. Adoptive immunotherapy for cancer: harnessing the T cell response. Nat Rev Immunol (2012) 12(4):269-81. doi:10.1038/nri3191

Conflict of Interest Statement: The authors declare that the research was conducted in the absence of any commercial or financial relationships that could be construed as a potential conflict of interest.

Copyright (c) 2016 Comrie and Burkhardt. This is an open-access article distributed under the terms of the Creative Commons Attribution License (CC BY). The use, distribution or reproduction in other forums is permitted, provided the original author(s) or licensor are credited and that the original publication in this journal is cited, in accordance with accepted academic practice. No use, distribution or reproduction is permitted which does not comply with these terms. 